The final publication is available at Elsevier via http://dx.doi.org/10.1016/j.bmc.2016.05.052 @ 2016.

\title{
The Action Mechanism of Daptomycin
}

\author{
Scott D. Taylor, Michael Palmer \\ Department of Chemistry, University of Waterloo, Waterloo, ON N2L 3G1, Canada
}

\begin{abstract}
Daptomycin is a lipopeptide antibiotic produced by the soil bacterium Streptomyces roseosporus that is clinically used to treat severe infections with Grampositive bacteria. In this review, we discuss the mode of action of this important antibiotic. Although daptomycin is structurally related to amphomycin and similar lipopeptides that inhibit peptidoglycan biosynthesis, experimental studies have not produced clear evidence that daptomycin shares their action mechanism. Instead, the best characterized effect of daptomycin is the permeabilization and depolarization of the bacterial cell membrane. This activity, which can account for daptomycin's bactericidal effect, correlates with the level of phosphatidylglycerol (PG) in the membrane. Accordingly, reduced synthesis of PG or its increased conversion to lysyl-PG promotes bacterial resistance to daptomycin. While other resistance mechanisms suggest that daptomycin may indeed directly interfere with cell wall synthesis or cell division, such effects still await direct experimental confirmation. Daptomycin's complex structure and biosynthesis have hampered the analysis of its structure activity relationships. Novel methods of total synthesis, including a recent one that is carried out entirely on a solid phase, will enable a more thorough and systematic exploration of the sequence space.
\end{abstract}

Keywords: calcium-dependent lipopeptide antibiotics, bacterial membranes, membrane potential

Email addresses: s5taylor@uwaterloo.ca (Scott D. Taylor), mpalmer@uwaterloo.ca (Michael Palmer) 


\section{Introduction}

Medical science relies heavily on antibiotics for treating bacterial infections. However, bacterial resistance against many antibiotics that have seen widespread use has become a major medical issue, and this problem is expected to become much more serious in the not-to-distant future. Fortunately, physicians have at their disposable a handful of antibiotics against which widespread resistance has not yet appeared. These antibiotics are used as a last defence against serious infections when other antibiotics fail. One of these so-called last-resort antibiotics is daptomycin (Figure 1).

The activity of daptomycin involves the cytoplasmic membrane; it is calcium-dependent and limited to Gram-positive bacteria, against which it has been in clinical use since 2003 (see sections 2 and 3). While daptomycin is a young drug, it quickly became to be widely used in clinical practice; nevertheless, bacterial resistance for now remains relatively rare. Nevertheless, cases of non-susceptibility during daptomycin therapy in clinically important organisms such as Staphylococcus aureus and Enterococcus faecium or E. faecalis are appearing with increasing frequency. ${ }^{1,2}$

With several other classes of antibiotics, most notably $\beta$-lactams, bacterial resistance has been countered by structural alterations to the drug molecules, which has greatly extended their useful lifespans. While such a strategy would appear worthwhile with daptomycin also, there are several challenges to overcome in this case. The molecule is larger and more complex than most other commonly used antibiotics, and the scope of semisynthetic modification is limited. The molecule is a peptide, but it is non-ribosomally synthesized, which makes the introduction of structural changes using molecular genetics a non-trivial undertaking (see section 8). Finally, while daptomycin has been shown to permeabilize bacterial membranes (see section 10.4), its action mode is still incompletely understood. Despite a large number of experimental studies, no macromolecular targets have been unambiguously identified, and neither have the strategic positions within the daptomycin molecule itself that are responsible for target interaction. Thus, before we can pursue rational strategies for modification that would improve daptomycin's activity and counter bacterial resistance, we will have to attain a better understanding of these molecular properties.

The purpose of this review is to present a detailed summary of the studies that have been performed to elucidate daptomycin's mode of action. The best-understood effect is permeabilization of the cytoplasmic membrane, 
which involves the formation of membrane-associated oligomers (see section 10.7). Several studies have reported inhibition of macromolecular biosynthesis, which may occur as a consequence of membrane permeabilization, or possibly through direct effects of daptomycin on specific macromolecular targets (see section 11). Aspects such as the history of daptomycin, its clinical development and use, pharmacokinetics, biosynthesis, bacterial resistance, as well as related antibiotics will be covered only to the extent required for an adequate understanding of the main subject. Readers interested in learning more about these topics are referred to several previous reviews. ${ }^{1-17}$

\section{History}

Daptomycin is a member of the A21978C group of calcium-dependent, cyclic lipopeptide antibiotics that were originally isolated from the fermentation broth of Streptomyces roseosporus by researchers at Eli Lily in the early 1980s. ${ }^{18,19}$ These compounds showed excellent activity against a variety of Gram-positive organisms, but they were inactive against Gram-negatives.

Eli Lily began the clinical development of daptomycin in 1985, but later abandoned it when they observed myopathic side effects during Phase II trials. In 1997, Cubist Pharmaceuticals Inc. (recently acquired by Merck \& Co.) licensed daptomycin and resumed clinical testing. They found that the myopathic side effects could be minimized by altering the dose regimen. ${ }^{20}$ These successful tests resulted in approval for clinical use beginning in 2003 (see next section).

\section{Antimicrobial spectrum and clinical use}

Daptomycin was approved for clinical use in the USA in 2003, and in Europe in 2006, for treating complicated skin and skin-structure infections caused by methicillin-susceptible and -resistant Staphylococcus aureus (MSSA and MRSA), Streptococcus pyogenes, Streptococcus agalactiae, Streptococcus dysgalactiae subsp. equisimilis, as well as vancomycin-susceptible Enterococcus faecalis. Furthermore, in 2006, approval was given for treatment of bacteraemia and right-sided endocarditis caused by MSSA and MRSA. ${ }^{3}$ Although many cyclic lipopeptide antibiotics have been discovered, ${ }^{4,5}$ daptomycin remains the only member of this class that is approved for clinical use.

A notable gap in the clinical action spectrum of daptomycin is Streptococcus pneumoniae, the leading cause of community-acquired pneumonia. While 
S. pneumoniae is highly susceptible in vitro, this does not translate into sufficient therapeutic activity in vivo. The likely cause for this discrepancy is the inhibition of daptomycin by lung surfactant, which binds and sequesters the drug. ${ }^{21}$ The inhibition may be related to its content of phosphatidylglycerol (see section 10.1). Efforts have been made to develop daptomycin derivatives that avoid surfactant inhibition (see section 8.3).

\section{Structure and biosynthesis}

The structure of daptomycin is shown in Figure 1. Daptomycin and all other members of the A21978C group of lipopeptides are synthesized by the same modular non-ribosomal synthetase system ${ }^{22}$ (see Figure 2) and contain the same peptide moiety; the only part of the structure that differs between them is the N-terminally attached fatty acyl residue. The common peptide moiety contains 13 amino acids, six of which are non-proteinogenic: D-Asn ${ }^{(2)}$, ornithine $\left(\mathrm{Orn}^{(6)}\right)$, D-Ala ${ }^{(8)}, \mathrm{D}-\mathrm{Ser}^{(11)},(2 \mathrm{~S}, 3 \mathrm{R})$-methylglutamate $\left(\mathrm{MeGlu}^{(12)}\right)$, and kynurenine $\left(\mathrm{Kyn}^{(13)}\right)$. The $\mathrm{C}$-terminal ten amino acids form a macrocyclic core, which contains a ring-closing depsi (ester) bond between the side chain of $\mathrm{Thr}^{(4)}$ and the $\alpha$-COOH of the C-terminal $\mathrm{Kyn}^{(13)}{ }^{23,24}$ The $\mathrm{N}$-terminal tripeptide protrudes from the ring and carries the variable fatty acyl residue, which is attached to $\operatorname{Trp}^{(1)}$.

The nature of the fatty acyl residue affects both antibacterial activity and toxicity; a decanoyl residue imparts the most favourable combination. ${ }^{26}$ This derivative, which became daptomycin (Dap), is only a minor product when S. roseosporus is fermented in conventional rich media. However, daptomycin can be produced as a major component by supplementing the fermentation medium with decanoic acid; ${ }^{27}$ this observation greatly facilitated its large scale production, purification and further development.

\section{Relationship to other calcium-dependent lipopeptide antibiotics}

There are two major groups of calcium-dependent lipopeptides, all of which are produced by soil bacteria that belong to Streptomyces or related genera. ${ }^{16}$ The group that contains daptomycin (or rather, the A21978C complex) also contains the A54145 group (Figure 1), as well as the so-called "calciumdependent antibiotic" (CDA). All of these are lipodepsipeptides, because the core macrocycle is closed by an ester bond. It seems likely that they also share 

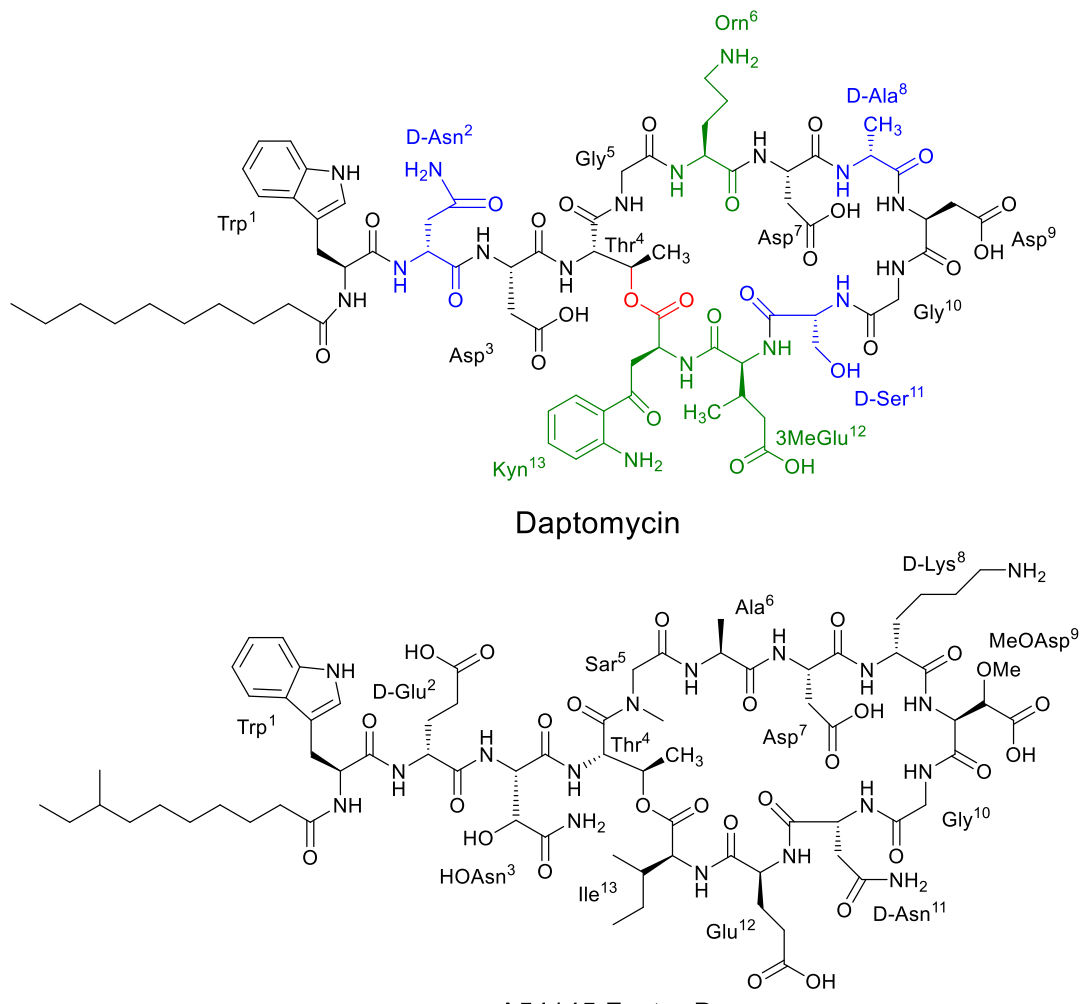

A54145 Factor D

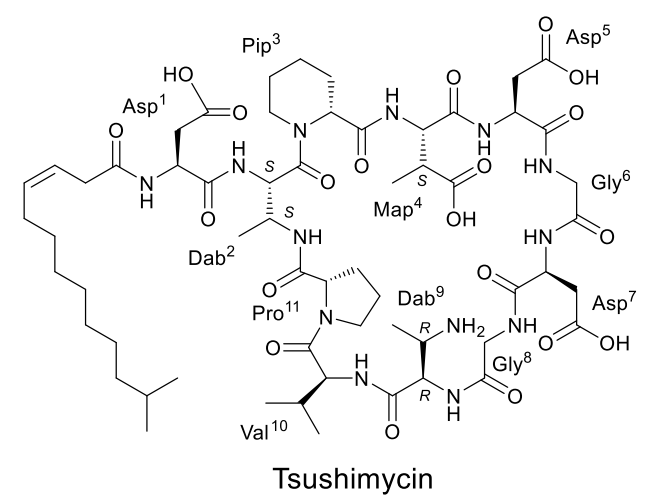

Figure 1: Structure of daptomycin (Dap) and the related $\mathrm{Ca}^{2+}$-dependent lipopeptide antibiotics A54145 Factor D and tsushimycin. In Dap, the non-proteinogenic amino acids are shown in blue (D-amino acids) and green. The ester bond is highlighted in red. MeGlu: (2S,3R)methylglutamate; Kyn: kynurenine, Orn: ornithine; Sar: sarcosine; MeOAsp: methoxyaspartate; HOAsn: hydroxyasparagine; Pip: pipecolinic acid; Map: $\beta$-methylaspartate; Dab: 2,3-diaminobutyric acid. 
A<smiles>[R]C(N)C(=O)O</smiles>

B

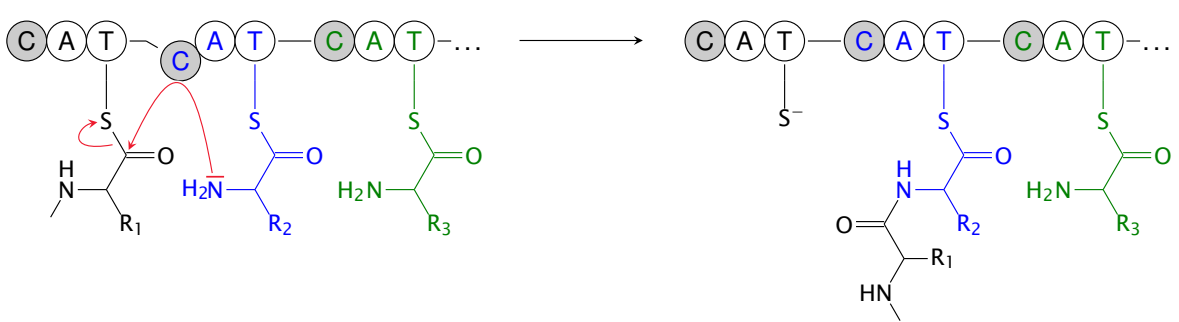

C

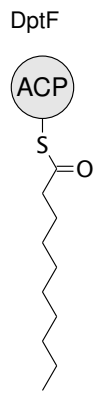

DptA<smiles>NC(Cc1c[nH]c2ccccc12)C(=O)Sc1ccccc1</smiles>

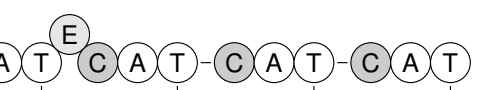

DptD

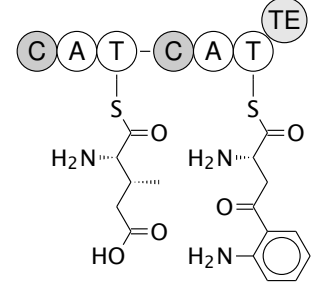

DptBC

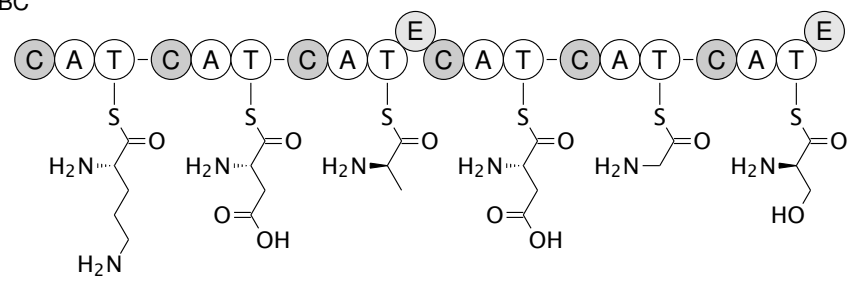

Figure 2: Schematic of the modular daptomycin synthetase. Each amino acid is incorporated by a cognate module that has a C-A-T domain structure and an optional E domain, which mediate condensation, activation, thiolation, and epimerization, respectively. A: Each amino acid is first adenylated by the A domain and then attached to the T domain of its cognate module. $\mathrm{B}$ : The $\mathrm{C}$ domain acquires the nascent peptide from the preceding module and attaches the amino acid to the peptide's $\mathrm{C}$-terminus through a peptide bond. C: The synthesis of the daptomycin peptide core is carried out in a sequence by three large enzymes (DptA, DptBC, and DptD). Each of these enzymes contains multiple amino acid-conferring modules. The DptF module supplies activated acyl tails to DptA. The thioesterase domain (TE) at the end of DapD cyclizes and releases the lipopeptide. Adapted from reference 25 with permission. 
the same mechanism of action, although functional studies are scarce for molecules other than daptomycin.

The second group contains tsushimycin (also shown in Figure 1) as well as amphomycin, laspartomycin, and several others. In these molecules, the peptide macrocycle is closed by an amide bond rather than an ester bond. The members of this group also share one action mechanism, which consists of binding and sequestering undecaprenol phosphate, a bacterial membrane constituent that is an essential carrier coenzyme in the assembly and membrane translocation of peptidoglycan precursors. This was shown first for amphomycin ${ }^{28,29}$ and more recently for friulimycin ${ }^{30}$ and laspartomycin. ${ }^{31}$

Structural homology is greater within each group, yet it is also considerable between them (cf. Figure 1). The macrocycles of both groups contain 10 amino acids. Within this ring, two acidic amino acids-corresponding to Asp ${ }^{(7)}$ and $\mathrm{Asp}^{(9)}$ in daptomycin - are conserved, and both are essential for the activity of daptomycin (section 8). Furthermore, positions that contain D-amino acids in one group are either conserved in the other or occupied by glycine and sarcosine, which are achiral, so that no incompatible steric constraints are imposed by the DL-isomerism of the peptide backbone. While the structural similarities between both groups have prompted researchers to look for a direct, specific inhibition by daptomycin of peptidoglycan synthesis also, no such effect has yet been substantiated. ${ }^{32}$

The similarity between the cyclic lipopeptide antibiotics also pertains to their synthetase systems. Through genetic recombination of these modular synthetases, hybrid lipopeptides can be generated. ${ }^{22}$ One such study explored a series of hybrids between daptomycin and A54145. ${ }^{33}$ A54145 is more toxic than daptomycin, but unlike the latter is not inhibited by lung surfactant. In initial testing, one particular hybrid compound appeared to combine the favourable traits of both, although no further confirmatory evidence has since been reported.

\section{Physiochemical Properties}

\subsection{Ionization state}

Daptomycin has six amino acid residues with ionizable side chains: four acidic residues and two residues containing primary amino groups (see Table 1). The $\mathrm{pK}_{\mathrm{a}}$ values of these residues in the absence of $\mathrm{Ca}^{2+}$ have been characterized by potentiometric titration, ultraviolet (UV) spectrophotometry, and NMR spectroscopy. ${ }^{34,35}$ At physiological $\mathrm{pH}$, all residues except Kyn ${ }^{(13)}$ will be 
Table 1: Ionizable amino acid residues of daptomycin and their $\mathrm{pK}_{\mathrm{a}}$ values

\begin{tabular}{llc}
\hline & Residue & $\mathrm{pK}_{\mathrm{a}}$ \\
\hline Anionic residues & $\mathrm{Asp}^{(3)}$ & 4.3 \\
& $\operatorname{Asp}^{(7)}$ & 1.0 \\
& $\operatorname{Asp}^{(9)}$ & 3.8 \\
& $\mathrm{mGlu}^{(12)}$ & 4.6 \\
\hline Cationic residues & $\mathrm{Kyn}^{(13)}$ & $0.8-1.3$ \\
& $\mathrm{Orn}^{(6)}$ & 10.7 \\
\hline
\end{tabular}

ionized; accordingly, daptomycin with no calcium bound (apo-daptomycin) exists primarily as a trianion. It may be noted that the $\mathrm{pK}_{\mathrm{a}}$ value for $\mathrm{Asp}^{(7)}$ is very low; the exact reason is not clear from the available structural information.

NMR studies carried on daptomycin in solution indicate that $\mathrm{Ca}^{2+}$ binds to daptomycin in a cooperative manner and with a 1:1 stoichiometry ${ }^{36,37}$ (see also section 7.2). Therefore, the $\mathrm{Ca}^{2+}$-bound form of daptomycin in solution exists as a monoanion.

\subsection{Intrinsic fluorescence}

Daptomycin contains two fluorophores: $\operatorname{Trp}^{(1)}$ and $\mathrm{Kyn}^{(13)}$. Since the emission spectrum of tryptophan overlaps the absorption spectrum of kynurenine, there is efficient Förster-type energy transfer between them, causing the $\operatorname{Tr}^{(1)}$ residue to have a very low quantum yield. ${ }^{38}$ The intrinsic fluorescence properties of daptomycin have been used extensively to probe the interaction of daptomycin with membranes (see section 10) as well as its aggregation in solution (see the following section).

\subsection{Aggregation of free daptomycin in solution}

Daptomycin's amphiphilic structure suggests that it may form aggregates in solution. This question has been studied with ${ }^{1} \mathrm{H}-\mathrm{NMR}^{36,39}$ and optical methods ${ }^{40}$ In the absence of calcium and at $\mathrm{pH} 7.4$ or higher, daptomycin aggregation is minimal or absent at millimolar concentrations, whereas under acidic conditions aggregates may form at concentrations as low as $0.12-0.2$ $\mathrm{mM}$. This $\mathrm{pH}$-dependent variation can be explained by the ionization state of apo-daptomycin. Between $\mathrm{pH} 2.5$ and 4, apo-daptomycin exists primarily as 
a neutral or monoanionic species. As the $\mathrm{pH}$ increases to 7, deprotonation of $\mathrm{Asp}^{(3)}$ and $\mathrm{mGlu}\left(\mathrm{u}^{(2)}\right.$ will cause the dianionic and trianionic forms to dominate.

\subsection{Calcium-induced aggregation and its role in daptomycin delivery to bac- terial cells}

Of potentially greater interest to the biological activity of daptomycin is its aggregation in $\mathrm{Ca}^{2+}$-bound form. $\mathrm{Ca}^{2+}$ will shield some of the negative charges, and one would therefore expect it to promote aggregation, as has indeed been reported in several studies. Since $\mathrm{Ca}^{2+}$-induced aggregation has been proposed to mediate the delivery of daptomycin to bacterial membranes, this topic will be discussed in some detail.

Ball et al. reported that the addition of as little as 0.3 equivalents of $\mathrm{Ca}^{2+}$ to daptomycin at $0.8 \mathrm{mM}$ and $\mathrm{pH} 5.0$ caused significant line broadening in the ${ }^{1} \mathrm{H}$-NMR spectrum, indicating the onset of aggregation. Line broadening increased up to 1 equivalent of $\mathrm{Ca}^{2+}$ and then ceased. ${ }^{36}$ The change in line width had a sigmoidal dependence on the amount of $\mathrm{Ca}^{2+}$ added, suggesting cooperative binding. The addition of $\mathrm{Ca}^{2+}$ did not result in discernible changes to chemical shifts. Rotondi and Gierasch also noted significant line broadening in the ${ }^{1} \mathrm{H}$-NMR spectrum of $1.5 \mathrm{mM}$ daptomycin at $\mathrm{pH} 5.3$ upon addition of $10 \mathrm{mM} \mathrm{Ca}^{2+} \cdot 39$

The effect of $\mathrm{Ca}^{2+}$ on daptomycin aggregation has also been studied using ultracentrifugation. ${ }^{41}$ With $2.5 \mathrm{mM}$ of daptomycin at $\mathrm{pH} 7.0$, no aggregation was observed up to 0.75 equivalents of $\mathrm{Ca}^{2+}$. However, micelles consisting of 14 daptomycin monomers formed once a 1:1 ratio of $\mathrm{Ca}^{2+}$ to daptomycin was reached. When $\mathrm{Ca}^{2+}$ was replaced with $\mathrm{Mg}^{2+}, 2.5$ of the salt equivalents were required to induce micelle formation.

Based on these experimental observations of $\mathrm{Ca}^{2+}$-induced aggregation in solution, it has been suggested that daptomycin micelles act as vehicles to deliver daptomycin to the bacterial cell membranes in high local concentrations and in a functional conformation. ${ }^{42}$ Once in contact with the bacterial membrane, the daptomycin micelle would then dissociate, allowing monomeric daptomycin to insert into the bilayer.

A similar view has been presented by Qiu et al., ${ }^{40}$ who observed the aggregation of native daptomycin by fluorescence at concentrations above 0.06 $\mathrm{mM}$ or $100 \mu \mathrm{g} / \mathrm{ml}$ in the presence of $1 \mathrm{mM} \mathrm{Ca}^{2+}$. However, such daptomycin concentrations still substantially exceed the MICs for clinically susceptible pathogens; they occur in human plasma only immediately after application of the drug; and moreover, $90 \%$ of the total amount of daptomycin in plasma is 
protein-bound, most likely in monomeric form, ${ }^{43,44}$ and the unbound remainder would remain well below the experimental aggregation threshold.

Fluorescence experiments using micromolar concentrations of two derivatives of daptomycin labelled with Alexa Fluor 350 and 7-nitro-2,1,3-benzoxadiazol (NBD-Dap; Figure 3) detected no FRET between both, with or without $\mathrm{Ca}^{2+}$ present, ${ }^{45}$ suggesting that aggregation does not occur at concentrations near the MIC. It cannot be ruled out, however, that the covalently attached fluorescent labels may have affected the extent of aggregation.

Overall, the micelle delivery mechanism is thus unsupported by relevant evidence; and considering that formation of large aggregates with multiple negative charges would hinder rather than facilitate daptomycin's permeation through the bacterial cell wall, it also lacks plausibility.

\section{Structural studies}

Knowing the structure of daptomycin in its various forms-free in solution, calcium-bound in solution, and bound to both calcium and susceptible target membranes-would be helpful for elucidating its mechanism of action. Some, but not all of these structures have been characterized by NMR.

\subsection{Solution structure of apo-daptomycin}

Three reports have appeared that describe the solution structure of apodaptomycin. ${ }^{36,39,42}$ All three arrive at different structures.

Jung et al. examined a $2 \mathrm{mM}$ solution of daptomycin at $\mathrm{pH} 6.6 .{ }^{42}$ As discussed above in section 6.3, apo-daptomycin should not aggregate under these conditions. They essentially found no preferred structure. A model of the structure closest to the ensemble average shows the backbone forming two bends at $\mathrm{Asp}^{(7)}$ and $\mathrm{Asp}^{(9)}$, with a highly variable region around Gly ${ }^{(5)}$ (see Figure $4 \mathrm{~B}$ ).

Rotondi and Gierasch used a $1.9 \mathrm{mM}$ solution of apo-daptomycin at $\mathrm{pH} 5.3$ for their NMR studies. ${ }^{39}$ From the findings described in section 6.3, one would expect apo-daptomycin to exist mainly as aggregates under these conditions. However, these workers reported that they avoided aggregation by adding solid daptomycin to a degassed buffer in successive small portions, each of which was allowed time to completely dissolve prior to the next addition. The welldefined and sharp lines of their spectra, better than those in the other two studies, support this claim. In contrast to Jung et al., Rotondi and Gierasch did find a preferred aqueous conformation for apo-daptomycin. The cyclic 

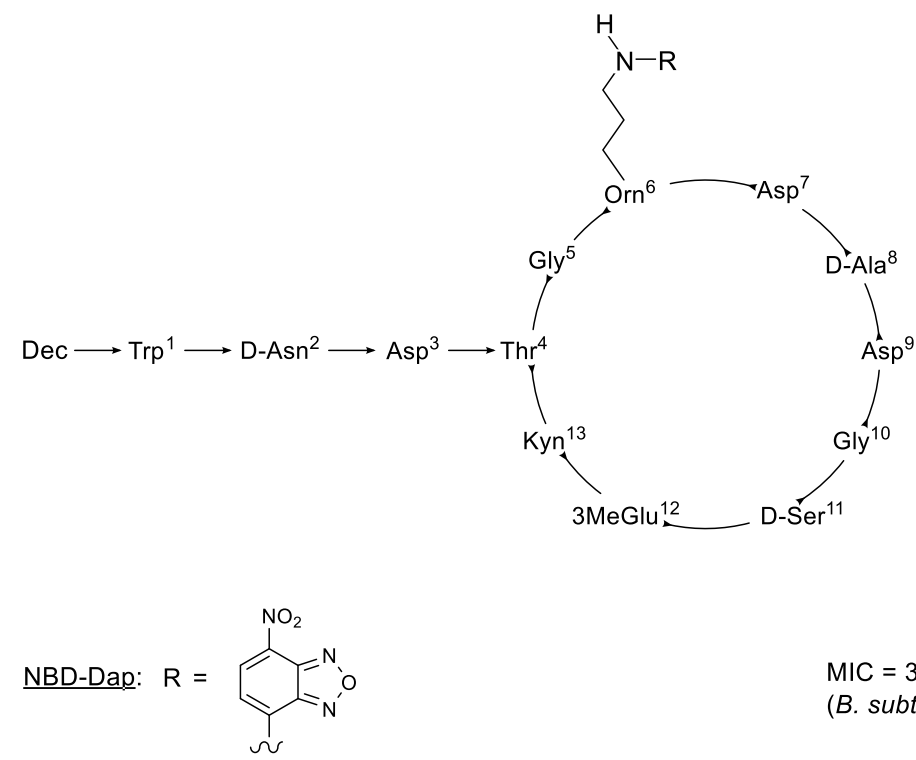

$\mathrm{MIC}=3 \mu \mathrm{g} / \mathrm{mL}$

(B. subtilis)

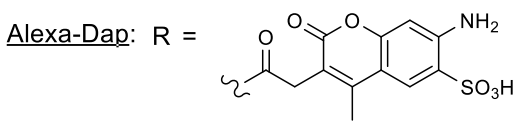

$\mathrm{MIC}=12 \mu \mathrm{g} / \mathrm{mL}$

(B. subtilis)

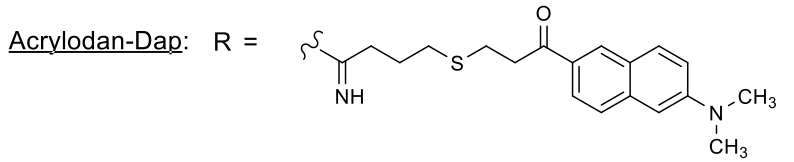

$\mathrm{MIC}=10 \mu \mathrm{g} / \mathrm{mL}$

(B. subtilis)

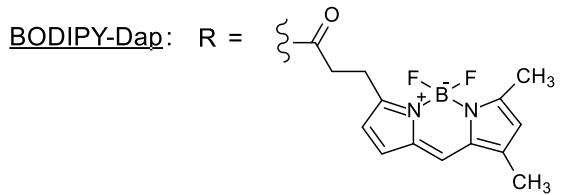

$\mathrm{MIC}=8 \mu \mathrm{g} / \mathrm{mL}$

(S. aureus)

Figure 3: Structures and antimicrobial activities of fluorescent derivatives used to study the interaction of daptomycin with membranes. All labels shown in this figure were attached to the unique amino group of the $\operatorname{Orn}^{(6)}$ side chain.

portion adopted a hairpin-like structure with a type II' $\beta$-turn centred on D$\mathrm{Ala}^{(8)} / \mathrm{Asp}^{(9)}$, and a pseudo- $\beta$-turn forming the other end of the hairpin at Kyn13/Thr-4. The acyl chain and the hydrophobic $\operatorname{Tr}^{(1)}$ and $\mathrm{Kyn}^{(13)}$ residues were clustered at one end of the hairpin, while polar neutral and ionic residues were situated at the other. 
A

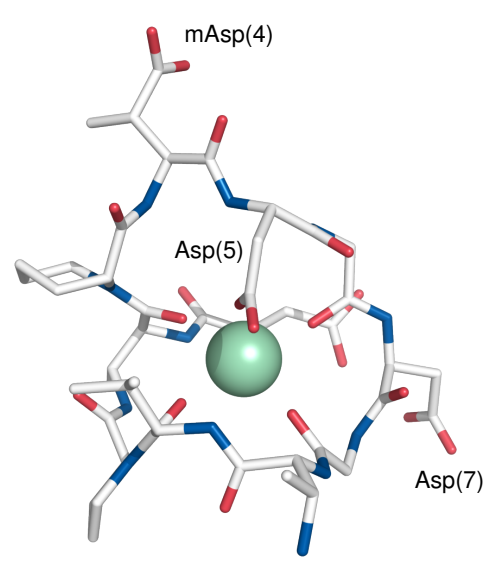

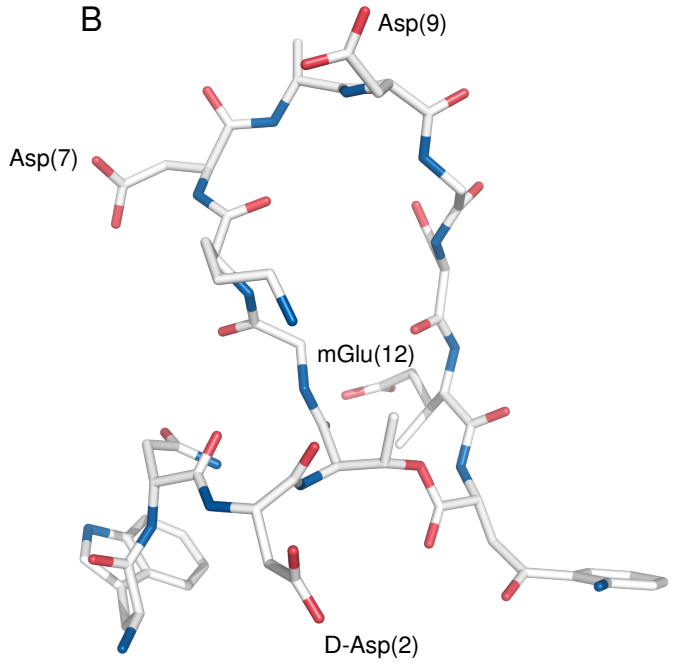

Figure 4: Crystal structure of tsushimycin, ${ }^{46}$ and NMR structure of daptomycin. ${ }^{42}$ A: In tsushimycin, $\mathrm{Ca}^{2+}$ is coordinated by Asp ${ }^{(5)}$ together with several backbone carbonyls from the ring. Additional calcium ions that bridge adjoining tsushimycin molecules in the crystal are not shown. B: In daptomycin, the ring has a looser structure, and the side chain carboxyl groups point away from the ring and from each other. $\mathrm{No}^{2+}$ binding site is obvious. In both structures, the fatty acyl tails have been omitted.

Ball et al. used a $0.8 \mathrm{mM}$ solution at $\mathrm{pH} 5.0$ for their NMR studies on apodaptomycin. ${ }^{36}$ Some aggregation of apo-daptomycin would be expected to occur under these conditions. A preferred aqueous conformation for apo-daptomycin was also reported. Their best quality structure indicated an extended conformation with turns at D-Ala ${ }^{(8)}$ and $\mathrm{Gly}^{(10)} / \mathrm{D}-\mathrm{Ser}^{(11)}$. The backbone amide groups were oriented inwards, while most of the peptide side-chain groups protruded outwards from the decapeptide ring and appeared exposed to solvent. The decanoyl residue was flexible with a large degree of conformational freedom. They suggested that the four acidic residues, $\mathrm{Asp}^{(3)}, \mathrm{Asp}^{(7)}, \mathrm{Asp}^{(9)}$ and $\mathrm{mGlu}^{(12)}$ are not close enough to each other to render an effective $\mathrm{Ca}^{2+}$ binding site.

\subsection{Solution structure of calcium-bound daptomycin}

Two reports have appeared describing the structure of $\mathrm{Ca}^{2+}$-bound daptomycin. ${ }^{36,42}$ The Hancock group reported the a structure obtained using samples of $2 \mathrm{mM}$ daptomycin with $5 \mathrm{mM} \mathrm{Ca}^{2+}$ at $\mathrm{pH}$ 6.6. ${ }^{42}$ Under these conditions, some line broadening was noted, indicating some extent of aggregation. Their structure of the $\mathrm{Ca}^{2+}$-bound daptomycin was found to be better defined than 
their structure of apo-daptomycin, as several medium and long range Nuclear Overhauser Effects (NOEs) were observed, whereas only sequential NOEs were found for apo-daptomycin. In their $\mathrm{Ca}^{2+}$-bound structure, the ring was less circular, and the side chain of Asp $^{(3)}$ was tucked underneath the ring. They proposed that a $\mathrm{Ca}^{2+}$ binding site might exist between $\mathrm{Asp}^{(3)}$ and $\mathrm{Asp}^{(7)}$. Moreover, the side chains were redistributed, and there was an increase in the amount of hydrophobic surface exposed to solvent. This suggested to them that daptomycin undergoes a significant conformational change upon binding $\mathrm{Ca}^{2+}$.

Rotondi and Gierasch ${ }^{39}$ as well as Bunkoczi et al. ${ }^{46}$ pointed out that, since Straus et al. had used conditions of incipient aggregation, some or all of their measured medium and long range NOEs might have arisen from intermolecular interactions. Realizing that daptomycin aggregation may have affected their results, Straus et al. re-examined their $\mathrm{Ca}^{2+}$-bound daptomycin structure in detail. ${ }^{37}$ Molecular dynamics (MD) simulations suggested that the conformational change in daptomycin upon binding $\mathrm{Ca}^{2+}$ might not be as significant as originally proposed. It was concluded that none of the $\mathrm{Ca}^{2+}$-bound daptomycin models tested in the MD simulations were consistent with the NOE restraints reported earlier, and that the previously reported NOE restraints between residues $\mathrm{Asp}^{(3)}$ and $\mathrm{Ala}^{(8)}$ were intermolecular and should not been included during structure refinement. Overall, these studies led to a revised structure for $\mathrm{Ca}^{2+}$-bound daptomycin that did not differ significantly from their previously reported apo-daptomycin structure. This conclusion is consistent with CD measurements, which showed only minor spectral changes upon addition of $\mathrm{Ca}^{2+}$ to daptomycin in solution. ${ }^{42} \mathrm{No} \mathrm{Ca}^{2+}$ binding site was obvious in the refined structure. They also determined the structure of daptomycin $(2 \mathrm{mM})$ in the presence of $5 \mathrm{mM} \mathrm{MgCl} 2 \cdot{ }^{37}$ No line broadening was observed, and the obtained structure closely resembled their previously reported apo-daptomycin structure. ${ }^{42}$

Ball et al. also reported the structure of $\mathrm{Ca}^{2+}$-bound daptomycin using an $0.8 \mathrm{mM}$ solution of daptomycin at $\mathrm{pH} 5.3 .{ }^{36}$ There were no major differences between their $\mathrm{Ca}^{2+}$-daptomycin structure and their apo-daptomycin structure.

\subsection{Structure of daptomycin bound to phospholipid micelles}

The Straus group has reported the structure of daptomycin in 1,2-dihexanoyl-sn-glycero-3-phosphocholine (DHPC) micelles in the presence of calcium, ${ }^{47}$ which resembled the apo-daptomycin structure. Therefore, it was as-

sumed that daptomycin experiences only a minor conformational rearrange- 
ment upon binding to DHPC micelles in the presence of $\mathrm{Ca}^{2+}$. It should be noted, however, that with respect to both geometry and lipid composition, such micelles are likely not a very accurate model for susceptible lipid bilayers (see section 10.1).

\subsection{Structure of tsushimycin}

The solid state structure of daptomycin has not been reported. However, the crystal structure of another cyclic lipopeptide antibiotic, tsushimycin (Figure 1), has been determined at $1.0 \AA$ resolution. ${ }^{46}$ The peptide backbone resembles a saddle with a long tail. $\mathrm{A} \mathrm{Ca}^{2+}$ ion is bound in the middle of the saddle by interaction with the side-chains of two Asp groups (Asp ${ }^{(1)}$ and $\operatorname{Asp}^{(5)}$ ), four backbone carbonyl $\mathrm{O}$ atoms $\left(\mathrm{Dab}^{(2)}, \mathrm{Gly}^{(6)}, \mathrm{Gly}^{(8)}\right.$ and $\left.\mathrm{Val}^{(10)}\right)$, and a water molecule (see Figure 4A).

The peptide forms a dimer whose subunits are linked reciprocally via hydrogen bonds between the side chain carboxyl group of Asp ${ }^{(7)}$ of one molecule and side chain amino group and amide N-H of $\mathrm{Dab}^{(9)}$ of the other. The carboxyl groups of $\operatorname{Asp}^{(7)}$ and $\mathrm{Asp}^{(1)}$ in one molecule of the dimer interacts with an additional $\mathrm{Ca}^{2+}$ ion that lies on the surface. The side chain and carbonyl group of $\mathrm{Dab}^{(9)}$ of the other molecule interact with a water molecule that also binds to the peripheral $\mathrm{Ca}^{2+}$. The dimers are also connected by an interaction between the peripheral $\mathrm{Ca}^{2+}$ and the carboxyl groups of $\mathrm{mAsp}^{(4)}$. There is a tunnel through the centre of the dimer, which is large enough to accommodate a phospholipid molecule. Hydrophobic residues together with the fatty acyl chains surround a cavity, while the charged groups of the molecules point outside, resulting in a polar surface.

None of the daptomycin NMR structures are similar to the solid state structure of tsushimycin. ${ }^{11}$ Nevertheless, Asp ${ }^{(1)}$ and Asp ${ }^{(5)}$ in tsushimycin, which participate in the binding of the central $\mathrm{Ca}^{2+}$ ion, are conserved in Dap, in which they correspond to Asp ${ }^{(3)}$ and Asp ${ }^{(7)}$, respectively. However, studies with a daptomycin analog having D-Asn at positions 2 and 3 and Glu at position 12 suggest that $\mathrm{Asp}^{(3)}$ may not be highly important for Dap's antibacterial activity (see section 8). Moreover, it has been pointed out that $\mathrm{Dab}^{(9)}$ in tsushimycin, which is important for dimer formation, corresponds to $\mathrm{Ser}^{(11)}$ in Dap, which agrees with the observation that the biologically relevant species of daptomycin is not a dimer (see section 10.7). 


\subsection{Conclusions from NMR structural studies on Dap}

The above NMR studies suggest that apo-daptomycin in aqueous solution is highly mobile as evidenced by the fact that three groups arrived at different structures for apo-daptomycin. Although the daptomycin structures obtained by the different groups differed in detail, they also showed broad conformational similarities highlighting the amphipathic nature of the molecule. Moreover, daptomycin does not appear to undergo a large conformation change upon binding $\mathrm{Ca}^{2+}$ or upon binding to DHPC micelles in the presence of $\mathrm{Ca}^{2+}$. While the available structures may be useful for developing testable hypotheses concerning structure-activity relationships, they do not capture the conformational change that occurs when daptomycin interacts with susceptible target membranes.

\section{Structure-activity relationships}

In order to understand the action mode of daptomycin, detailed structureactivity relationship (SAR) studies would be of great value. However, for the most part, this work still remains to be done.

\subsection{Calcium binding sites}

Daptomycin in solution binds calcium stoichiometrically (section 7.2), whereas membrane-bound daptomycin binds two equivalents of calcium (see section 10.8). Neither of the two binding sites has been experimentally identified. It has been observed that daptomycin and all other $\mathrm{Ca}^{2+}$-dependent cyclic lipopeptide antibiotics contain a DXDG or EF-hand motif, ${ }^{10}$ which mediates calcium binding in calmodulin and related proteins. ${ }^{48}$ Moreover, replacement of either aspartate residue in this motif with alanine or asparagine abolishes antimicrobial activity. ${ }^{49,50}$ However, in tsushimycin, only one of these two aspartate residues participates directly in coordinating the centrally bound $\mathrm{Ca}^{2+}$ ion, and in the available structures of daptomycin it is not obvious how they might cooperate in $\mathrm{Ca}^{2+}$ binding (see Figure 4). Also note that, in daptomycin and A54145, the " $\mathrm{X}$ " position between the two aspartate residues is taken by a D-amino acid, which would likely alter the affinity for calcium.

NMR experiments as well as analogue studies suggest that $\mathrm{Kyn}^{(13)}$ and mGlu ${ }^{(12)}$ may also be involved in binding to $\mathrm{Ca}^{2+}$ (see section 8.3). 


\subsection{Role of the fatty acyl tail}

In early studies it was noted that the lipid tail was essential for biological activity. Removal of the lipid results in complete loss of biological activity, as did the hydrolysis of the ring-closing ester bond. ${ }^{23}$ Semisynthetic $n$-acyl variants showed antimicrobial activity increasing with the length of the acyl chain up to ten carbons. Beyond this length, in vitro activity increased with some, but not other bacterial strains; in vivo activity showed no further improvement. ${ }^{26}$ In a planar lipid bilayer model, conductance increased with acyl chain length from decanoyl to dodecanoyl and tridecanoyl residues. Insertion of phenylalanine or similar residues between the fatty acyl group and the $\mathrm{N}$-terminal tryptophan caused only minor effects on activity. ${ }^{26}$ Replacement of the decanoyl residue with pyrene- or perylene-butanoic acid-performed for the sake of fluorescence studies, see section 10.1 - caused only minor reduction in antimicrobial activity. ${ }^{51}$ Overall, it appears that the specific structure of the fatty acyl residue is less important than its overall hydrophobicity.

\subsection{Functional effects of single or combined amino acid substitutions}

Although biosynthetic, chemoenzymatic, and total chemical synthesis methodologies have been developed that allow for specific amino acid substitutions to be made in Dap, only a fairly limited number of analogues have been prepared using these methodologies and examined for biological activity, and not all of the amino acid positions have been explored (see Table 2).

Marahiel and co-workers developed a chemoenzymatic approach, in which synthetic linear peptide precursors are circularized using a recombinantly expressed thioesterase enzyme. Using this method, they prepared nine daptomycin analogues and examined their in vitro biological activity (against B. subtilis PY79). ${ }^{50}$ At the time of this report, it was not known that daptomycin contains D-Asn rather than L-Asn at position 2; this was discovered only a short time afterwards. ${ }^{24}$ Moreover, in all of their analogues, mGlu was replaced with Glu. Consequently, most of their analogues were triple mutants containing Glu in place of $\mathrm{mGlu}^{(12)}$, the unintended L-Asn ${ }^{(2)}$ substitution, as well as an additional substitution of interest at a third position within the peptide. Since it has been shown that the L-Asn ${ }^{(2)}$ analogue ${ }^{24}$ is 10 -fold, and the $\mathrm{Glu}^{(12)}$ analogue $^{33} 12$-fold less active than native daptomycin, their results should be interpreted with caution with respect to the effect of specific single amino acid substitutions. Nevertheless, some important information was obtained from these studies, namely that Asp residues 7 and 9 appear to be essential for 
biological activity, as the L-Asn ${ }^{(2)} / \mathrm{Glu}^{(12)} / \mathrm{Asn}^{(7)}$ and L-Asn ${ }^{(2)} / \mathrm{Glu}^{(12)} / \mathrm{Asn}^{(9)}$ analogues were inactive. ${ }^{50}$ Since the $\mathrm{L}-\mathrm{Asn}^{(2)} / \mathrm{Glu}^{(12)} / \mathrm{Asn}^{(3)}$ and the L-Asn ${ }^{(2)} / \mathrm{Glu}^{(12)}$ analogues were 26- and 7-fold less active than daptomycin, respectively, it appears that $\mathrm{Asp}^{(3)}$ and $\mathrm{mGlu}^{(12)}$ are important but not essential for activity.

Nguyen et al. have prepared nine daptomycin analogues using engineered hybrid synthetases to substitute one or several amino acid residues in A54145, mostly using the homologous residues from daptomycin or CDA. The hybrid lipopeptides were tested for activity against $S$. aureus ${ }^{33}$ in the absence or presence of lung surfactant. They found that Trp or Ile can replace Kyn ${ }^{(13)}$ with only a 2 and 4 -fold loss of activity, respectively. D-Asn ${ }^{(11)}$ can be replaced with DAla or D-Ser, and D-Ala ${ }^{(8)}$ with D-Ser, with remarkably little effect on biological activity. In contrast, replacing D-Ala ${ }^{(8)}$ with D-Asn causes a 12-fold decrease in activity. Generally, most reciprocal exchanges between daptomycin and A54145 had only minor effects on activity.

Several analogues of daptomycin have recently been prepared by total chemical synthesis and examined for biological activity against B. subtilis. ${ }^{49,52}$ Replacing $\mathrm{Kyn}^{(13)}$ with Tyr, or (2S,3R)-MeGlu ${ }^{(12)}$ with (2S,3S)-MeGlu or $\mathrm{Thr}^{(4)}$ with Ser resulted in a 35 to 60 -fold loss of activity at $5 \mathrm{mM} \mathrm{Ca}^{2+}$. Interestingly, at increased calcium concentrations, the activity of these peptides increased greatly and approached that of native daptomycin, which suggests that these modifications mainly affect $\mathrm{Ca}^{2+}$ affinity but might have little effect on other aspects of daptomycin's action mechanism. A Glu ${ }^{(12)} / \mathrm{Trp}^{(13)}$ analogue exhibited activity approaching that of daptomycin. ${ }^{49}$ In contrast, an $\mathrm{Ala}^{(7)} / \mathrm{Glu}^{(12)} / \operatorname{Trp}^{(13)}$ analogue was completely inactive even at very high $\mathrm{Ca}^{2+}$ concentration, which is consistent with $\mathrm{Asp}^{(7)}$ being crucial for $\mathrm{Ca}^{2+}$ interactions and Dap's activity. ${ }^{52}$

Martin et al. reported the total chemical synthesis of two daptomycin analogues and their enantiomers and evaluated their activity against $S$. aureus. ${ }^{54}$ In both analogues, mGlu ${ }^{(12)}$ was replaced with Glu and $\mathrm{Thr}^{(4)}$ with L-diaminopropionic acid, thus replacing the ring-closing ester linkage with an amide linkage. In one of the analogues, a third substitution was introduced $\left(\mathrm{Kyn}^{(13)}\right.$ was replaced with Trp). These two analogues were 100 to 200 -fold less active than daptomycin, which illustrates the importance of the ester bond to biological activity. Interestingly, the enantiomers were completely devoid of activity, indicating that a specific chiral interaction is required for activity.

Using a semi-synthetic approach to analogue synthesis, He et al. have shown that $\operatorname{Trp}^{(1)}$ can be replaced with a surprisingly wide variety of unnatural aromatic amino acids and still retain good activity against $S$. aureus. ${ }^{55} \mathrm{In}$ 
Table 2: Antibacterial activities of daptomycin analogues with single or multiple amino acid substitutions. Ellipses indicate residues that are retained from native daptomycin.

\begin{tabular}{|c|c|c|c|c|c|c|c|c|c|c|c|c|c|c|}
\hline \multirow[t]{2}{*}{ Peptide $^{\mathrm{a}}$} & \multicolumn{13}{|c|}{ Amino acid position } & \multirow[t]{2}{*}{ MIC ratio ${ }^{b}$} \\
\hline & 1 & 2 & 3 & 4 & 5 & 6 & 7 & 8 & 9 & 10 & 11 & 12 & 13 & \\
\hline Dap & Trp & D-Asn & Asp & Thr & Gly & Orn & Asp & D-Ala & Asp & Gly & D-Ser & mGlu & Kyn & 1 \\
\hline $1^{24}$ & $\ldots$ & L-Asn & $\ldots$ & $\ldots$ & $\ldots$ & $\ldots$ & $\ldots$ & $\ldots$ & $\ldots$ & $\ldots$ & $\ldots$ & $\ldots$ & $\ldots$ & 10 \\
\hline $2^{50}$ & $\ldots$ & L-Asn & Asn & $\ldots$ & $\ldots$ & $\ldots$ & $\ldots$ & $\ldots$ & $\ldots$ & $\ldots$ & $\ldots$ & Glu & $\ldots$ & 27 \\
\hline $3^{50}$ & $\ldots$ & L-Asn & $\ldots$ & $\ldots$ & $\ldots$ & $\ldots$ & Asn & $\ldots$ & $\ldots$ & $\ldots$ & $\ldots$ & Glu & $\ldots$ & $\infty^{\mathrm{e}}$ \\
\hline $4^{50}$ & $\ldots$ & L-Asn & $\ldots$ & $\ldots$ & $\ldots$ & $\ldots$ & $\ldots$ & $\ldots$ & Asn & $\ldots$ & $\ldots$ & Glu & $\ldots$ & $\infty^{\mathrm{e}}$ \\
\hline $5^{50}$ & $\ldots$ & L-Asn & $\ldots$ & $\ldots$ & $\ldots$ & $\ldots$ & $\ldots$ & $\ldots$ & $\ldots$ & $\ldots$ & $\ldots$ & Gln & $\ldots$ & 10 \\
\hline $6^{50}$ & $\ldots$ & L-Asn & $\ldots$ & $\ldots$ & $\ldots$ & $\ldots$ & $\ldots$ & $\ldots$ & $\ldots$ & $\ldots$ & D-Asp & Glu & $\ldots$ & $>100$ \\
\hline $7^{50}$ & $\ldots$ & L-Asn & $\ldots$ & $\ldots$ & $\ldots$ & $\ldots$ & $\ldots$ & $\ldots$ & $\ldots$ & $\ldots$ & $\ldots$ & Glu & $\operatorname{Trp}$ & 33 \\
\hline $8^{50}$ & $\ldots$ & L-Asn & $\ldots$ & $\ldots$ & $\ldots$ & Lys & $\ldots$ & $\ldots$ & $\ldots$ & $\ldots$ & $\ldots$ & Glu & Trp & 33 \\
\hline $9^{33}$ & $\ldots$ & $\ldots$ & $\ldots$ & $\ldots$ & $\ldots$ & $\ldots$ & $\ldots$ & $\ldots$ & $\ldots$ & $\ldots$ & $\ldots$ & $\ldots$ & $\operatorname{Trp}$ & 2 \\
\hline $10^{33}$ & $\ldots$ & $\ldots$ & $\ldots$ & $\ldots$ & $\ldots$ & $\ldots$ & $\ldots$ & $\ldots$ & $\ldots$ & $\ldots$ & $\ldots$ & $\ldots$ & Ile & 4 \\
\hline $11^{33}$ & $\ldots$ & $\ldots$ & $\ldots$ & $\ldots$ & $\ldots$ & $\ldots$ & $\ldots$ & $\ldots$ & $\ldots$ & $\ldots$ & $\ldots$ & $\ldots$ & Val & 8 \\
\hline $12^{33}$ & $\ldots$ & $\ldots$ & $\ldots$ & $\ldots$ & $\ldots$ & $\ldots$ & $\ldots$ & $\ldots$ & $\ldots$ & $\ldots$ & $\ldots$ & Glu & $\ldots$ & 16 \\
\hline $13^{33}$ & $\ldots$ & $\ldots$ & $\ldots$ & $\ldots$ & $\ldots$ & $\ldots$ & $\ldots$ & $\ldots$ & $\ldots$ & $\ldots$ & D-Ala & $\ldots$ & $\ldots$ & 2 \\
\hline $14^{33}$ & $\ldots$ & $\ldots$ & $\ldots$ & $\ldots$ & $\ldots$ & $\ldots$ & $\ldots$ & $\ldots$ & $\ldots$ & $\ldots$ & D-Asn & $\ldots$ & $\ldots$ & 2 \\
\hline $15^{33}$ & $\ldots$ & $\ldots$ & $\ldots$ & $\ldots$ & $\ldots$ & $\ldots$ & $\ldots$ & D-Lys & $\ldots$ & $\ldots$ & D-Asn & $\ldots$ & $\ldots$ & 2 \\
\hline $16^{53}$ & $\ldots$ & $\ldots$ & $\ldots$ & $\ldots$ & $\ldots$ & $\ldots$ & $\ldots$ & $\ldots$ & $\ldots$ & $\ldots$ & D-Asn & Glu & $\ldots$ & 64 \\
\hline $17^{53}$ & $\ldots$ & $\ldots$ & $\ldots$ & $\ldots$ & $\ldots$ & $\ldots$ & $\ldots$ & $\ldots$ & $\ldots$ & $\ldots$ & D-Asn & $\ldots$ & Ile & 8 \\
\hline $18^{53}$ & $\ldots$ & $\ldots$ & $\ldots$ & $\ldots$ & $\ldots$ & $\ldots$ & $\ldots$ & D-Asn & $\ldots$ & $\ldots$ & $\ldots$ & $\ldots$ & $\ldots$ & 16 \\
\hline $19^{53}$ & $\ldots$ & $\ldots$ & $\ldots$ & $\ldots$ & $\ldots$ & $\ldots$ & $\ldots$ & D-Asn & $\ldots$ & $\ldots$ & $\ldots$ & Glu & $\ldots$ & 256 \\
\hline $20^{53}$ & $\ldots$ & $\ldots$ & $\ldots$ & $\ldots$ & $\ldots$ & $\ldots$ & $\ldots$ & D-Asn & $\ldots$ & $\ldots$ & $\ldots$ & $\ldots$ & Ile & 32 \\
\hline $21^{33}$ & $\ldots$ & $\ldots$ & $\ldots$ & $\ldots$ & $\ldots$ & $\ldots$ & $\ldots$ & D-Ser & $\ldots$ & $\ldots$ & $\ldots$ & $\ldots$ & $\ldots$ & 2 \\
\hline $22^{49,52}$ & $\ldots$ & $\ldots$ & $\ldots$ & $\ldots$ & $\ldots$ & $\ldots$ & $\ldots$ & $\ldots$ & $\ldots$ & $\ldots$ & $\ldots$ & $\mathrm{mGlu}^{\mathrm{c}}$ & $\ldots$ & $40-50$ \\
\hline $23^{52}$ & $\ldots$ & $\ldots$ & $\ldots$ & $\ldots$ & $\ldots$ & $\ldots$ & $\ldots$ & $\ldots$ & $\ldots$ & $\ldots$ & $\ldots$ & $\ldots$ & Tyr & 47 \\
\hline $24^{49,52}$ & $\ldots$ & $\ldots$ & $\ldots$ & $\ldots$ & $\ldots$ & $\ldots$ & $\ldots$ & $\ldots$ & $\ldots$ & $\ldots$ & $\ldots$ & Glu & $\operatorname{Trp}$ & $2-5$ \\
\hline $25^{49}$ & $\ldots$ & $\ldots$ & $\ldots$ & Ser & $\ldots$ & $\ldots$ & $\ldots$ & $\ldots$ & $\ldots$ & $\ldots$ & $\ldots$ & Glu & Trp & $>100$ \\
\hline $26^{49}$ & $\ldots$ & $\ldots$ & $\ldots$ & $\ldots$ & $\ldots$ & $\ldots$ & Ala & $\ldots$ & $\ldots$ & $\ldots$ & $\ldots$ & Glu & $\operatorname{Trp}$ & $\infty^{\mathrm{e}}$ \\
\hline $27^{54}$ & $\ldots$ & $\ldots$ & $\ldots$ & $\operatorname{Dapa}^{\mathrm{d}}$ & $\ldots$ & $\ldots$ & $\ldots$ & $\ldots$ & $\ldots$ & $\ldots$ & $\ldots$ & Glu & $\ldots$ & 200 \\
\hline $28^{54}$ & $\ldots$ & $\ldots$ & $\ldots$ & $\operatorname{Dapa}^{\mathrm{d}}$ & $\ldots$ & $\ldots$ & $\ldots$ & $\ldots$ & $\ldots$ & $\ldots$ & $\ldots$ & Glu & $\operatorname{Trp}$ & 100 \\
\hline $29^{55}$ & Phe & $\ldots$ & $\ldots$ & $\ldots$ & $\ldots$ & $\ldots$ & $\ldots$ & $\ldots$ & $\ldots$ & $\ldots$ & $\ldots$ & $\ldots$ & $\ldots$ & 4 \\
\hline $30^{55}$ & Tyr & $\ldots$ & $\ldots$ & $\ldots$ & $\ldots$ & $\ldots$ & $\ldots$ & $\ldots$ & $\ldots$ & $\ldots$ & $\ldots$ & $\ldots$ & $\ldots$ & $>32$ \\
\hline
\end{tabular}

${ }^{a}$ numbered citations refer to the main reference list at the end of the article

${ }^{\mathrm{b}}$ MIC of analog/MIC of daptomycin

${ }^{\mathrm{c}}$ this analogue contained (2S,3S)-3-methylglutamate, i.e. the diastereomer of the native amino acid residue

${ }^{\mathrm{d}}$ Dapa $=$ L-diaminopropionic acid

e $\infty$ indicates complete loss of activity

contrast to Dap, some of these analogues were also active in the presence of lung surfactant.

Many daptomycin analogues have been made by modification of the Orn ${ }^{(6)}$ amino group. ${ }^{56,57}$ The amino group was found not to be essential for antibac- 
terial activity as many of these analogues retained good biological activity though retention of at least one NH proton in the derivatized Orn side-chain was important for retaining potency. The role of the amino group in the mode of action is unknown.

\section{Cellular sites of action}

The bacterial cell membrane was recognized early on as the major target site of daptomycin. In 1987, Allen et al. reported that daptomycin, in a calciumdependent manner, caused $\mathrm{K}^{+}$leakage from Staphylococcus aureus cells. ${ }^{58}$ Cell fractionation experiments detected daptomycin bound to cell walls and cell membranes, but not to cytosolic constituents. ${ }^{59}$ The latter study also reported that daptomycin inhibits the biosynthesis of cell wall macromolecules, and the authors proposed inhibition of lipoteichoic acid biosynthesis as daptomycin's major mode of action. Several studies have attempted to determine whether daptomycin indeed directly blocks some enzyme or substrate in cell wall biosynthesis, or alternatively, inhibition of macromolecular synthesis occurs downstream of membrane permeabilization and loss of key metabolites; this question remains controversial (see section 11).

Sublethal concentrations of daptomycin were found to cause elongation of bacterial cells, which suggested that daptomycin interferes with cell division. ${ }^{59}$ This observation has been substantiated and extended in subsequent studies (see section 10.10).

\section{Interactions with membranes}

Daptomycin's effect on bacterial membranes has been the subject of numerous studies with both cells and model membranes. The findings of these studies largely complement each other, but some of the effects observed with model membranes are probably of limited significance in vivo.

\subsection{Lipid specificity}

Early studies with model membranes used mostly phosphatidylcholine (PC) membranes, sometimes supplemented with cholesterol. ${ }^{38,60}$ Daptomycin bound to such membranes in a calcium-dependent manner, as evidenced by an increase in quantum yield and a spectral blue shift in the fluorescence emission of $\operatorname{Kyn}^{(13)}, 38,61$ and it also permeabilized them, as detected using planar 


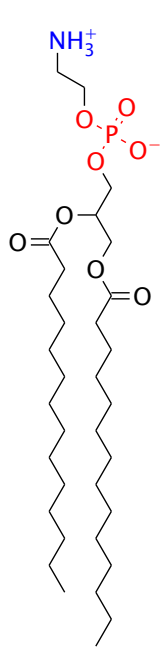

$\mathrm{PE}$

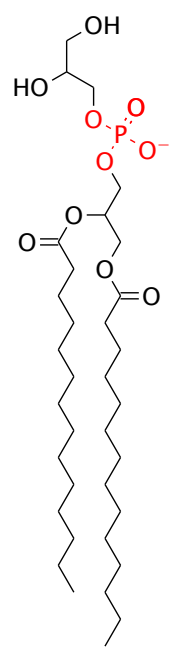

$P G$

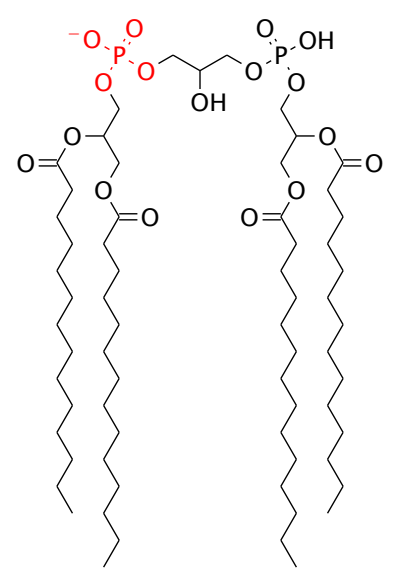

cardiolipin $(\mathrm{CL})$
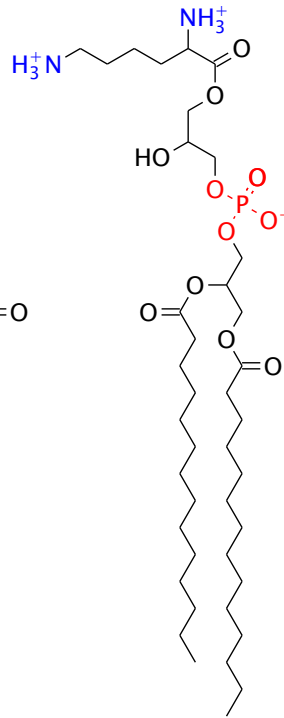

lysyl-PG

Figure 5: Major phospholipids of Gram-positive bacteria. Phosphatidylethanolamine (PE) is the major neutral phospholipid, whereas phosphatidylglycerol (PG) and cardiolipin (CL) are acidic; with CL, only one of the phosphate groups is usually deprotonated. Lysyl-PG carries a net positive charge. While the figure shows the myristoyl variants of all lipids, the fatty acyl residues in vivo are subject to variation in length and degree of unsaturation.

bilayer conductivity. ${ }^{60}$ Membranes of such lipid composition are conventionally used as models for animal cell membranes; they are not, however, very similar to typical bacterial cytoplasmic membranes, which are richer in acidic phospholipids. Since daptomycin is selective for bacterial membranes, the question arose what role acidic lipids might have in its activity. The two acidic phospholipids phosphatidylglycerol and cardiolipin (Figure 5) are abundant in bacterial membranes, ${ }^{62}$ and as it turns out, both affect the function of daptomycin. At least some of these effects can be observed both with bacterial cells and with model membranes.

$\mathrm{CD}$ spectroscopy indicates that even in the presence of $\mathrm{Ca}^{2+}$ daptomycin undergoes only a minor, if any, conformational transition when binding to pure PC membranes; however, the conformation changes profoundly on membranes containing both PC and PG. ${ }^{42}$ Inclusion of PG in model membranes also significantly enhances the fluorescence quantum yield of Kyn ${ }^{(13)}$, suggesting that this residue becomes more deeply buried in the lipid bilayer. ${ }^{42}$ The conformational change induced by PG was ascribed to a bridging interaction 
between it and one of the acidic residues in daptomycin, ${ }^{42}$ and it may be correlated to the formation of daptomycin oligomers, which also depends on the presence of PG in the membrane (see section 10.7).

The evidence regarding the stoichiometric ratio of daptomycin to PG is somewhat conflicting. Fluorescence studies using perylene-labelled daptomycin and a lipid bicelle system consisting of DMPC, DMPG, and dihexanoylPC produced a maximal perylene excimer signal at an equimolar ratio of peptide and PG, suggesting that the interaction is stoichiometric. ${ }^{51}$ In contrast, isothermal titration calorimetry (ITC) using daptomycin and DOPC/DOPG liposomes suggests that each daptomycin molecule binds two molecules of PG. ${ }^{63}$ One possible explanation for the discrepancy is that the lipopeptide molecules interact with both leaflets of the bicelle but with only the outer leaflet of the liposome. Alternatively, the fluorescence assay and ITC might report on different stages of daptomycin's membrane interaction that require only one and two molecules of PG, respectively. In either case, a defined stoichiometric ratio suggests that PG interacts with daptomycin directly, rather than only indirectly through influencing bulk properties of the membrane such as lateral phase or charge segregation.

A key role of PG in the action mechanism of daptomycin is also supported by observations with bacterial cells. Fluorescently labelled daptomycin preferentially binds to PG-enriched membrane domains in Bacillus subtilis cells. ${ }^{64}$ Susceptible bacterial species such as Staphylococcus aureus contain large amounts of PG in the cytoplasmic membrane, and mutations that reduce its abundance are associated with decreased susceptibility (see section 12). Interestingly, Streptomyces species, which are Gram-positive organisms and therefore should in principle be susceptible to daptomycin, generally contain very little PG. ${ }^{65}$ It seems possible that this trait lets Streptomyces roseosporus, daptomycin's producer organism, avoid the bactericidal effect of its own poison, although no experimental data seem to be available on the PG content of this particular species.

While cardiolipin has been implicated in interactions with daptomycin by several lines of evidence, its role in the action mechanism is less well-defined, and its net effect on daptomycin activity is less certain. Inclusion of $10 \% \mathrm{CL}$ in model membranes causes more avid membrane binding of daptomycin, as evidenced by both ITC and monolayer compression experiments. ${ }^{66}$ However, in the liposome model at least, CL inhibits membrane permeabilization, ${ }^{66}$ which suggests that it might mediate resistance to daptomycin by competing for it with PG. Such an effect has indeed been claimed to occur in vivo, ${ }^{67}$ but 
the CL-enriched membrane domains purported in that study were identified by staining with nonyl-acridine orange, which has since been shown to bind to phosphatidylglycerol also. ${ }^{68}$ Thus, no conclusive evidence is available to support a preferential interaction between daptomycin and CL in vivo (see also section 12).

Since phosphatidylglycerol is rare in mammalian cell membranes, daptomycin's requirement for this lipid may explain its low toxicity for humans. However, the interaction of daptomycin with mammalian membrane constituents has not been systematically studied. Interestingly, the lipid composition of lung surfactant differs significantly from that of cell membranes. While dipalmitoyl-PC is the most prominent constituent, PG contributes up to $10 \%$ of the total lipid in lung surfactant. ${ }^{69}$ This relatively high PG content may be involved in the inhibition of daptomycin by surfactant (see section 3).

\subsection{Role of bacterial proteins in daptomycin membrane binding}

Boaretti and Canepari used affinity chromatography to isolate daptomycinbinding proteins from Enterococcus hirae cell membranes. ${ }^{70,71}$ Binding of the proteins to immobilized daptomycin was $\mathrm{Ca}^{2+}$-dependent, but EDTA failed to elute the bound proteins. While this behaviour appears surprising, it does resemble the binding of daptomycin to intact membranes, as observed in the same studies.

The authors propose that the isolated proteins are related to lipoteichoic acid biosynthesis, disruption of which they maintain to be the major action mechanism of daptomycin. However, the amino acid sequences of these proteins were not determined, nor have their biochemical activities been characterized. While potentially of great significance, their actual relevance to daptomycin's action mechanism therefore remains unknown.

\subsection{Distribution of cell-bound daptomycin}

In Bacillus subtilis, fluorescently labelled daptomycin (BODIPY-Dap; Figure 3) binds preferentially to division septa and in forespore membranes. ${ }^{64,72}$ The remainder of the cell surface is non-uniformly labelled, in a pattern that has been described as spiral-shaped ${ }^{64}$ or patchy. ${ }^{72}$ Daptomycin-rich membrane areas also bind labelled vancomycin and penicillin derivatives, suggesting that daptomycin, too, may bind to one of the substrates or enzymes involved in peptidoglycan synthesis. ${ }^{72}$ An alternative interpretation is based on membrane curvature; daptomycin is proposed to prefer "negative curvature," 
or concave membrane surfaces in the case of the septum, and "positive curvature," or convex surfaces, in case of the forespore membrane. ${ }^{72}$ It should be noted, however, that in the latter study it was not ascertained how the bound daptomycin was distributed between the inner and the outer membrane leaflets. The outer leaflet is concave where the inner one is convex, and vice versa; therefore, any curvature preference that daptomycin may have cannot be diagnosed with certainty from the reported findings.

The daptomycin-enriched membrane areas, in particular the septum, were also found to attract DivIVA, ${ }^{72}$ a protein involved in the control of cell division, which may link daptomycin binding to the aberrant cell division and morphology that has been observed in several studies (section 10.10).

\subsection{Membrane depolarization}

Using a $\mathrm{K}^{+}$-selective electrode, Allen et al demonstrated that daptomycin promoted the loss of intracellular $\mathrm{K}^{+}$from Staphylococcus aureus cells immediately after exposure to the drug and calcium. ${ }^{58}$ Similarly, Silverman et al. employed a $\mathrm{K}^{+}$-sensitive fluorescent probe to demonstrate that $5 \mu \mathrm{g} / \mathrm{ml}$ daptomycin can trigger $\mathrm{K}^{+}$release from S. aureus suspended in Hepes buffer $(\mathrm{pH}$ 7.2). ${ }^{73} \mathrm{~K}^{+}$release is accompanied by a collapse of membrane potential, as evidenced by the release of the membrane-permeant cation tetraphenylphosphonium; in contrast, the transmembrane $\mathrm{pH}$ gradient remains unaffected, as shown by the unaltered cellular accumulation of acetylsalicylic acid (ASA), a weak acid organic acid whose protonated form equilibrates across the membrane. ${ }^{74}$ Daptomycin inhibits the cellular uptake of amino acids by active transport, which depends on the membrane potential. ${ }^{75}$

Since the potassium concentration is higher inside the cell than outside, a $\mathrm{K}^{+}$-selective membrane permeabilization (as is induced by the ionophore valinomycin for example) would hyperpolarize rather than depolarize the membrane. The fact that daptomycin causes depolarization suggests that permeabilization is in fact not $\mathrm{K}^{+}$-selective. This is borne out by in vitro experiments with liposomes (see section 10.5).

\subsection{Functional size and solute specificity of the membrane defect}

Several lines of evidence indicate that daptomycin does not induce large defects in the cell membrane. Studies using both scanning electron microscopy (SEM) and transmission electron microscopy (TEM) indicate that daptomycin does not cause cell lysis of $S$. aureus and E. faecalis, although some morphological changes are observed. ${ }^{76,77}$ With Staphylococcus aureus in liquid culture, 
daptomycin at $4 \mu \mathrm{g} / \mathrm{ml}$ produced a $10^{3}$-fold decrease in cell viability with no concomitant drop in optical density. ${ }^{76}$ Electron microscopy showed that the cells remained intact, and the cell membranes free of discontinuities, but formation of aberrant division septa was common. When the cells were loaded with calcein, an anionic fluorescent small molecule, the dye was retained after exposure to daptomycin even after the cells had lost viability. Similarly, the nucleic acid stain TO-PRO3 remained excluded by cells even after treatment with daptomycin. ${ }^{76}$

Another nucleic acid stain whose exclusion by cell membranes is often used as an indicator of cell viability is propidium iodide. Using this assay, a fraction of the cells in a liquid culture of Staphylococcus epidermidis were found to be permeabilized after daptomycin treatment. ${ }^{32}$ Such findings should be interpreted with caution, however. Propidium is very similar in structure to ethidium, which is widely used as a model substrate for bacterial efflux systems. ${ }^{78}$ These efflux systems are driven by ion gradients or ATP, both of which vanish when daptomycin takes effect. ${ }^{79}$ This suggests that penetration of the dye may measure the cell's residual metabolic capacity for powering efflux rather than membrane continuity. Similar considerations may apply to Sytox Green, which like ethidium and propidium is an organic, aromatic cation with affinity for DNA. This dye enters cells only after prolonged exposure to daptomycin; ${ }^{72}$ the steep increase in DNA staining between 25 and 30 minutes under that study's experimental conditions is quite striking and would be surprising if dye uptake were controlled simply by passive diffusion.

Liposome studies of membrane permeabilization have reported somewhat divergent findings. Jung et al. reported that high concentrations of daptomycin $(30 \mu \mathrm{g} / \mathrm{ml})$ caused very little calcein leakage from DOPC liposomes but $100 \%$ calcein leakage from DOPC/DOPG liposomes. ${ }^{42}$ Surprisingly, preincubation of daptomycin with $\mathrm{Ca}^{2+}$ was required for the maximal effect. If the same concentrations were added separately to the calcein-loaded DOPC/DOPG liposomes, less than $10 \%$ leakage was observed even at $16 \mu \mathrm{g} / \mathrm{mL}$ daptomycin. Later, this same group, in collaboration with others, using essentially the same assay, reported only $7 \%$ calcein release from DOPC/PG liposomes at $32 \mu \mathrm{g} / \mathrm{mL}$ of daptomycin, ${ }^{32}$ which seems more in line with the previously discussed results obtained with bacterial cells. ${ }^{76}$

Using a coupled fluorescence assay that is based on the $\mathrm{pH}$-sensitive indicator pyranine, ${ }^{80}$ Zhang et al. recently demonstrated that daptomycin can form pores in DMPC/DMPG (1:1) liposomes. ${ }^{81}$ The pores are selective for cations, with permeabilities being highest for $\mathrm{Na}^{+}, \mathrm{K}^{+}$, and other alkali metal ions. The 
permeability was approximately twice lower for $\mathrm{Mg}^{2+}$, and even lower for the organic cations choline and hexamethonium. Daptomycin-induced leakage of $\mathrm{K}^{+}$was slow compared with that of valinomycin, a $\mathrm{K}^{+}$-specific ionophore, at comparable concentrations. Anions were excluded, as was the zwitterion cysteine. Such permeability properties would account for the loss of $\mathrm{K}^{+}$and the depolarization of bacterial cells, but also for their continued exclusion or retention of dye molecules, particularly anionic ones such as calcein, after exposure do daptomycin.

\subsection{Depletion of substrates and metabolic energy}

While there is no conclusive evidence that the daptomycin membrane lesion is permeable for any solutes other than small cations, daptomycin-exposed cells nevertheless become depleted of ATP concomitantly with cation loss and membrane depolarization. ${ }^{79}$ ATP regeneration by oxidative phosphorylation will stall when the membrane potential collapses, and moreover the loss of cellular $\mathrm{Mg}^{2+}$, which normally stabilizes ATP, should also contribute to ATP depletion. The depletion of amino acids due to the failure of active uptake $^{75}$ was already noted earlier (see section 10.4).

ATP depletion should disrupt macromolecular biosynthesis. Indeed, Laganas et al. have demonstrated that daptomycin, at twice its MIC, inhibited all macromolecular synthesis in Staphylococcus aureus, Enterococcus faecalis, and Enterococcus hirae. ${ }^{82}$ Similarly, Hobbs et al. found that the synthetic pathways for DNA, RNA, protein and peptidoglycan all become simultaneously inhibited, and that this inhibition occurs on a similar time scale to the loss of ATP. ${ }^{79}$

From the above observations, the question naturally arises whether membrane permeabilization also controls the time course of bactericidal action. While this question was answered in the affirmative by Silverman et al., ${ }^{73}$ Hobbs et al. maintain that the loss of cell viability precedes that of biosynthetic capacity. However, their reported kinetics of cell killing and biosynthetic collapse differ only by some minutes. ${ }^{79}$ Moreover, since daptomycin is tightly bound to the cell membrane, ${ }^{59}$ its effect will not be promptly terminated by dilution, and thus the time course of its bactericidal action cannot be accurately determined. Therefore, no substantial evidence contradicts the tenet that indeed membrane permeabilization sets the pace for bactericidal action. 


\subsection{Daptomycin oligomer formation}

Membrane-permeabilizing peptides and proteins quite commonly form oligomeric structures in the target membrane. Accordingly, the proposal by Silverman et al. ${ }^{73}$ that daptomycin also forms oligomeric membrane pores or channels was quite readily accepted, although at the time no experimental evidence of oligomer formation had been obtained. More recently, Muraih et al. ${ }^{45}$ demonstrated oligomer formation on liposomes and on bacterial membrane vesicles by FRET, using the $\mathrm{Kyn}^{(13)}$ residue of unlabelled daptomycin as the donor and an extrinsic NBD moiety attached to $\mathrm{Orn}^{(6)}$ as the acceptor (NBDdaptomycin, Figure 3). When NBD-daptomycin was used alone, oligomer formation was also evident by self-quenching of the dye. Oligomerization was dependent on $\mathrm{Ca}^{2+}$ and on the presence of PG in the target membranes. Subsequently, the FRET assay was used to measure the number of subunits contained in one daptomycin oligomer, which was found to be approximately 6-7 in DMPG/DMPC (1:1) liposomes. ${ }^{83}$

A series of experiments by Zhang et al. addressed the relevance of oligomer formation for daptomycin's antibacterial activity. ${ }^{63}$ These experiments used mixtures of daptomycin and of CB-182,462, a semi-synthetic derivative of A54145 (Figure 1). Hybrid oligomers were detected on both liposomes and on bacterial cells using FRET and other fluorescence assays. The hybrids resembled homogeneous oligomers in thermodynamic stability; they had, however, less than additive antibacterial activity.

If each individual lipopeptide molecule contributed independently and proportionally to the antibacterial effect, combinations of the two antibiotics should display strictly additive activity. The observation that they inhibit each other within hybrid oligomers indicates that the oligomer subunits are not functionally independent; therefore, the oligomeric state is indeed relevant to daptomycin's antibacterial activity.

\subsection{Topology of membrane-associated daptomycin}

Since the membrane-associated oligomer is involved in daptomycin's bactericidal effect, a detailed model of its three-dimensional structure would be of great value. However, no such model is as yet available; while NMR structures have been obtained for daptomycin in solution and with phosphatidylcholine micelles, no such studies have been reported using a suitable model of a susceptible membrane. Therefore, all available information on the topology derives from fluorescence studies and is of low resolution. Nevertheless, some useful insights have been obtained concerning the distribution of daptomycin 
A

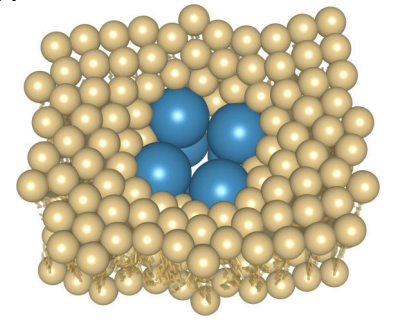

$B$

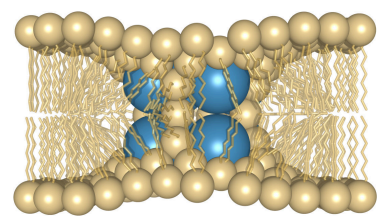

C

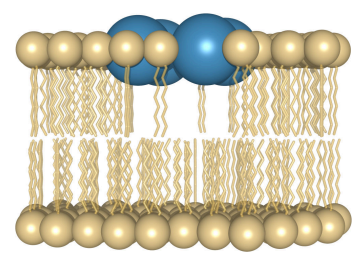

Figure 6: Hypothetical model of the membrane-associated daptomycin oligomer. A and B: Top and side view of the octamer that spans both leaflets and forms a functional pore. C: A tetrameric form that is confined to the outer leaflet has been observed on membranes containing cardiolipin ${ }^{66}$ and may also occur at sub-saturating calcium concentrations. ${ }^{84}$

across the two membrane leaflets, the positions of individual residues relative to the bilayer, and the mutual proximity of residues within the oligomer.

While daptomycin will initially interact with the outer membrane leaflet, the fact that it permeabilizes the target membrane suggests that it will ultimately penetrate the inner leaflet also. This question was studied using NBDdaptomycin, which is susceptible to reduction by the membrane-impermeant reducing agent diothionite. On susceptible (PC/PG) model membranes, only half of the membrane-bound NBD-daptomycin was immediately reduced by dithionite, suggesting that the remainder resided in the inner leaflet. Intriguingly, inclusion of cardiolipin in the liposomes rendered all NBD subject to immediate reduction, suggesting that daptomycin was restricted to the outer leaflet. Concomitantly, membrane permeabilization was inhibited, and the number of subunits in the daptomycin oligomer was reduced to four. From these findings, the hypothetical octameric structure shown in Figure 6 was proposed. ${ }^{66}$

Various fluorescence studies have identified membrane-inserted residues. The intrinsic fluorescence of $\mathrm{Kyn}^{(13)}$ undergoes a strong blue-shift and increase in quantum yield. ${ }^{38,42}$ The fluorescence of $\operatorname{Trp}^{(1)}$ becomes protected from quenching by iodide upon membrane binding. ${ }^{41}$ Since A54145 does not contain kynurenine, the fluorescence of its $\operatorname{Trp}^{(1)}$ residue is not attenuated by FRET, and the stronger signal allows a clear blue-shift to be observed upon membrane binding. ${ }^{85}$ Residues 1 and 13 are therefore membrane-inserted. Emission blue-shifts and increased quantum yields are also observed with the extrinsic labels NBD and acrylodan attached to $\mathrm{Orn}^{(6)}$ in daptomycin and 
to Lys ${ }^{(8)}$ in A54145, indicating that these residues, too, assume membrane-inserted positions. ${ }^{45,63,85}$

When the fluorescence of all four residues-1, 6, 8, and 13-are monitored at different calcium concentrations, it turns out that the spectral changes that signal membrane insertion occur at lower calcium concentrations with residues 6 and 8 than with residues 1 and 13, ${ }^{85}$ suggesting that residues 6 and 8 insert in a partially $\mathrm{Ca}^{2+}$-saturated state of daptomycin, whereas residues 1 and 13 insert only at full $\mathrm{Ca}^{2+}$ saturation. This agrees with the observation by ITC that, in the presence of PC/PG liposomes in molar excess, each daptomycin molecule binds two $\mathrm{Ca}^{2+}$ ions. ${ }^{85}$ Concomitantly with insertion of residues 1 and 13, the fluorescence of acrylodan-labelled residues 6 and 8 decreases due to self-quenching, indicating that these residues are involved in the interaction between adjacent subunits in the oligomer. ${ }^{85}$

Proximity also exists between the fatty acyl tails of adjacent oligomer subunits. This is evident from the excimer fluorescence of perylene or pyrene incorporated into the acyl residues of daptomycin ${ }^{51}$ and A54145, ${ }^{84}$ respectively (see Figure 7). In spite of their direct attachment to $\operatorname{Trp}^{(1)}$, excimer fluorescence-and thus, aggregation of fatty acyl residues-arises already in the partially $\mathrm{Ca}^{2+}$-saturated state, ${ }^{84}$ while $\operatorname{Trp}^{(1)}$ responds only at full $\mathrm{Ca}^{2+}$ saturation. Intriguingly, global analysis of time-resolved excimer fluorescence indicates that, even at partial $\mathrm{Ca}^{2+}$ saturation, membrane-bound $\mathrm{A} 54145$ already exists as an oligomer, which however has a lower number of subunits that the one observed at full saturation. ${ }^{84}$ This observation may be related to the proposed occurrence of daptomycin tetramers as intermediates of pore formation (see Figure 6). In this context, it is also worth mentioning that daptomycin may interact with membranes even in the absence of calcium, as shown by fluorescence polarization anisotropy in an early study, ${ }^{38}$ although this observation does not indicate oligomer formation.

\subsection{Membrane fusion, flip-flop, and lipid extraction}

Several studies have reported findings that are of potential interest, but whose relevance to daptomycin's in vivo activity is uncertain. PC/PG liposomes were observed to undergo fusion when exposed to daptomycin. ${ }^{41} \mathrm{Bac}$ terial cell membranes are surrounded by a cell wall that prevents fusion, and therefore it is clear that this experimental phenomenon does not directly translate to intact cells. Increased lipid flip-flop was demonstrated with a lipid analogue that incorporates the somewhat polar NBD label into a shorted acyl side chain, ${ }^{42}$ but not with a head group-labelled lipid probe. ${ }^{66}$ Both lipid analogues 

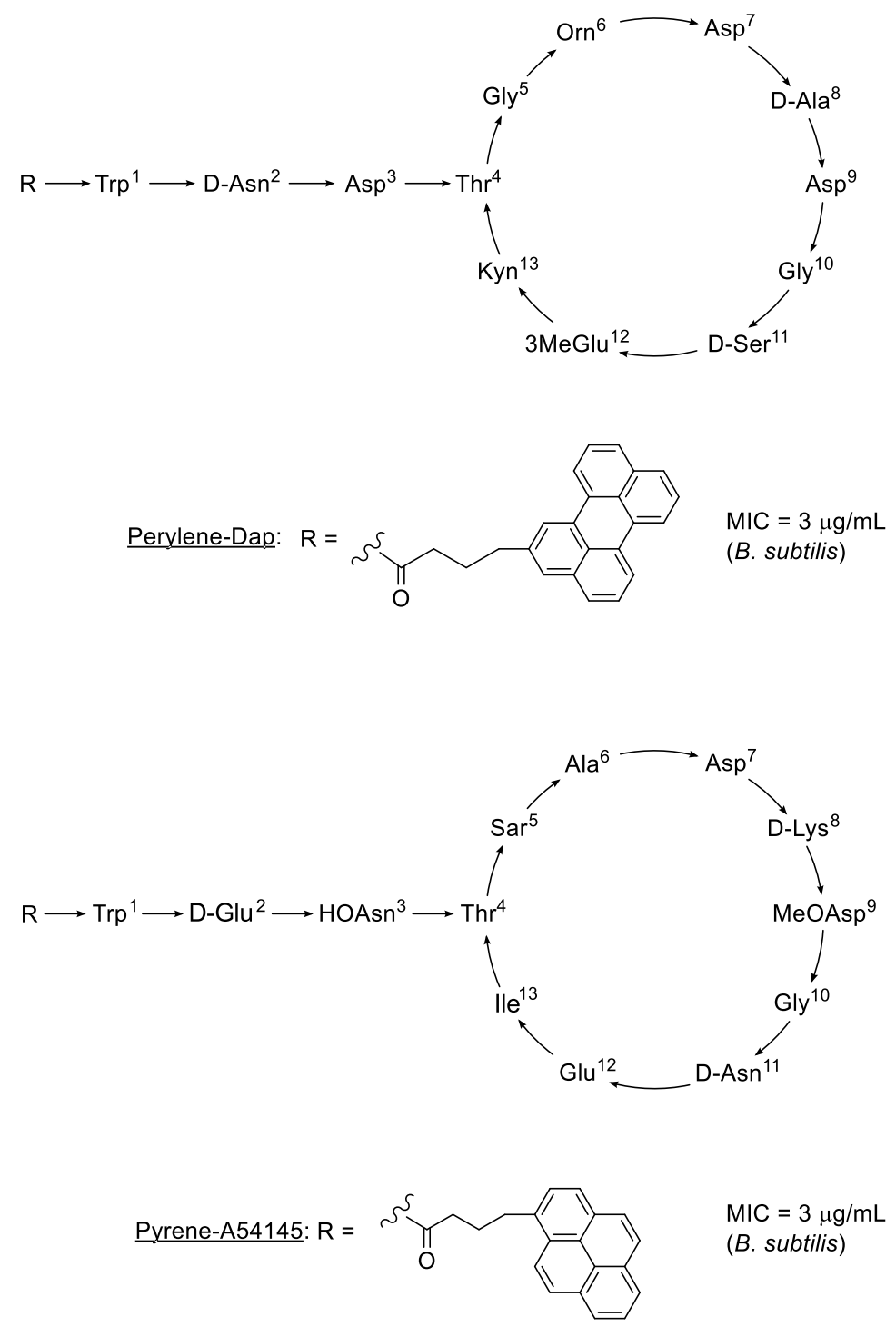

Figure 7: Structures and antimicrobial activities of perylene- and pyrene-labelled derivatives of daptomycin and A54145, respectively. Both can be used to track oligomer formation due to their excimer fluorescence. 
are synthetic, and thus the relevance of both of these observations to natural bacterial membranes remains uncertain.

Very recently, Huang and co-workers have proposed a novel mechanism for daptomycin-induced membrane damage. ${ }^{86}$ They employed fluorescence microscopy to monitor the interaction of daptomycin with giant unilamellar vesicles (GUVs) composed of DOPC/DOPG (7:3). The vesicles were, at the same time, partially pulled into a tube using constant suction. Exposure to daptomycin caused the vesicles to withdraw from the tube, indicating an increase in surface tension. Some, but not all, of the video sequences published by the authors showed that daptomycin was exuding from the vesicle membranes. From this, the authors concluded that lipids were being extracted also. However, while the extraction of lipids would indeed account for changes in surface tension, daptomycin might well affect surface tension in other ways, for example through changes in lipid packing and curvature strain. The authors proposed that lipid extraction accounts for daptomycin's antibacterial activity, but they did not provide any evidence for this hypothesis, nor did they specify how it might be substantiated experimentally.

\subsection{Effects on cell division and morphology}

Daptomycin's preference for division septa (see section 10.3) suggests that it interferes with cell division, which is also reflected in changes to the morphology of daptomycin-exposed cells. Elongated forms of Enterococcus and Bacillus cereus cells grown at MIC were reported in early studies. ${ }^{59}$ Bacillus subtilis cells grown with daptomycin at below MIC appeared bent and elongated. ${ }^{72}$ While elongated cell forms suggest that division is inhibited, the observation of additional, aberrant septa in Staphylococcus aureus ${ }^{76}$ could mean that cell division may be dysregulated rather than disrupted.

\section{Inhibition of macromolecular synthesis}

While membrane permeabilization appears to suffice for its bactericidal effect, daptomycin might nevertheless also specifically inhibit macromolecular biosynthesis pathways. A precedent for a dual action mechanism is provided by the lantibiotic nisin, which binds to lipid II and, like daptomycin, permeabilizes the membrane, but at the same time also disrupts peptidoglycan synthesis. ${ }^{87}$

We noted above that daptomycin-permeabilized cells become depleted of ions, substrates, and metabolic energy, which results in a general disruption of 
macromolecular biosynthesis also (see section 10.6). Therefore, to prove that daptomycin directly and specifically inhibits a given biosynthetic pathway, it is not enough to show this pathway to be obstructed in whole bacterial cells, and we must regard as inadmissible all reported evidence of this kind. Applying this filter leaves us with a rather manageable body of evidence, all of which is essentially negative.

\subsection{Lipoteichoic biosynthesis}

Canepari et al. reported that the synthesis of lipoteichoic acid is inhibited more readily than that of peptidoglycan in Enterococcus hirae whole cells. ${ }^{59}$ Such a preferential inhibition might arise from a requirement of LTA synthesis for some specific metabolite or ion that is lost particularly rapidly after permeabilization, and therefore does not prove a direct inhibition of the pathway.

Laganas et al., who re-examined inhibition of LTA biosynthesis and other pathways in E. hirae and other bacterial species, found no kinetic or dose specificity for LTA. ${ }^{82}$ They also investigated the possibility that the bactericidal activity of daptomycin might require ongoing LTA biosynthesis, even if it was not the primary target. In these experiments, Staphylococcus aureus and Enterococcus faecalis cells were treated with rifampicin, a bacteriostatic agent which causes complete cessation of macromolecular synthesis, including that of LTA, but does not cause significant loss in bacterial viability. The authors reasoned that, if concurrent LTA biosynthesis were required for the action of daptomycin, then pretreatment with rifampicin should protect bacteria from the lethal effect of daptomycin. In contrast to this prediction, however, exposure to daptomycin at eight times the MIC for 1 h effectively killed $S$. aureus both when exponentially growing and when growth-arrested with rifampicin. In contrast, rifampicin did protect $S$. aureus against ciprofloxacin, an antibiotic that inhibits DNA topoisomerase and is active only on actively growing cells. ${ }^{82}$

The findings by Laganas et al. show that LTA biosynthesis is not required for daptomycin activity. It is also unlikely that LTA itself is a target for daptomycin, since the antibiotic cannot be neutralized by simultaneous addition of purified LTA even at concentrations up to $500 \mu \mathrm{g} / \mathrm{ml}^{82}$

\subsection{Peptidoglycan synthesis}

The structural similarity between daptomycin and the amphomycin group of lipopeptide antibiotics suggested early on that, like the latter, daptomycin 
might inhibit peptidoglycan biosynthesis, and this possibility continues to attract interest.

Several early studies reported inhibitory effects on various steps in peptidoglycan biosynthesis; ${ }^{58,88,89}$ however, most of this evidence stems from whole bacterial cells and thus cannot be regarded as conclusive. A cell-free assay of peptidoglycan polymerization detected inhibition by daptomycin, but only at concentrations that were far beyond MIC. ${ }^{58}$

A recent study employed bacterial membrane preparations to compare the effect on LTA and peptidoglycan precursor synthesis of daptomycin, amphomycin, and an analogue of the latter (MX-2401). ${ }^{32} \mathrm{~A}$ strong inhibition was seen when amphomycin and its analogue were used in twofold molar excess over their known target bactoprenol phosphate. A twofold excess of daptomycin caused an inhibition by approximately $20 \%$. As discussed above, daptomycin forms oligomers with six or more subunits (see section 10.7). If we assume that each oligomer might neutralize no more than one or two carrier lipid molecules, it seems possible that a greater molar excess of daptomycin might cause a stronger inhibition. It may be worthwhile to repeat these experiments under such conditions.

\section{Resistance mechanisms}

Clinical cases of daptomycin non-susceptibility emerging during therapy have been documented in important pathogens such as Staphylococcus aureus as well as Enterococcus and Streptococcus species. ${ }^{3,5}$ Complete genome sequences of resistant strains have identified several mutational hot spots. While most of the genes in question are functionally related to the cell membrane and the cell wall, ${ }^{1,11}$ the phenotypic mechanism that links them to daptomycin susceptibility and resistance is understood only in a few cases. More research into the underlying bacterial physiology should also help to elucidate daptomycin's mode of action.

\subsection{Reduced synthesis of $P G$}

We had seen that PG facilitates daptomycin binding and permeabilization of membranes (section 10.1). In bacterial cells, PG is also the biosynthetic precursor of CL and of lysyl-PG. Accordingly, decreased biosynthesis of PG and its increased conversion to CL or lysyl-PG may all cause changes to bacterial susceptibility. The latter two lipids may also have their own specific effects on daptomycin susceptibility. 
The gene pgs $A$ encodes a CDP-diacylglycerolglycerol-3-phosphate 3-phosphatidyltransferase that is involved in the production of PG. Mutations that reduce its activity reduce membrane PG levels and daptomycin susceptibility in Bacillus subtilis and Staphylococcus aureus. ${ }^{64,90,91}$

\subsection{Lysyl-phosphatidylglycerol}

Lysyl-phosphatidylglycerol (lysyl-PG, see Figure 5) is a regular cell membrane constituent of Gram-positive bacteria. Its is formed from PG in a transesterification that uses lysyl-tRNA as a cosubstrate. The reaction is catalysed by the membrane protein MprF, which also supplies the translocase activity that subsequently transfers lysyl-PG from the inner to the outer membrane leaflet. ${ }^{92}$ The abundance of lysyl-PG in bacterial membranes correlates with resistance to both cationic antimicrobial peptides ${ }^{93}$ and daptomycin. Gainof-function mutations in the $m p r F$ gene cause increased lysyl-PG levels, decreased PG levels, and daptomycin resistance in Staphylococcus aureus (see reference 94 and citations therein). Conversely, deletion of $m p r F$ induces hypersensitivity to daptomycin. ${ }^{95}$

Since both amino groups of its lysyl residue are free, lysyl-PG carries a positive net charge. Electrostatic repulsion may be involved in the protection of bacterial cells from cationic antimicrobial peptides, and possibly also from $\mathrm{Ca}^{2+}$-saturated daptomycin, although model studies with liposomes suggest that the effect occurs after the peptides have become membrane-bound. ${ }^{96}$ Moreover, it has been shown that not all daptomycin-resistant isolates with mprF mutations exhibit changes in cell surface charge. ${ }^{97,98}$ Hence, it has been suggested that the mutations in $m p r F$ may simply be reducing the amount of PG in the cell membrane, which would affect daptomycin's ability to interact with the membrane and form functional oligomers. ${ }^{13}$

\subsection{Cardiolipin}

In model membranes, cardiolipin promotes membrane binding of daptomycin but inhibits permeabilization (section 10.1). This suggests that increased synthesis of CL could mediate bacterial resistance to daptomycin. Indeed, cardiolipin synthase mutants have been isolated from resistant mutants of Staphylococcus aureus ${ }^{91}$ as well Enterococcus species. ${ }^{99}$ Some of these mutants have been shown to have increased activity, ${ }^{100}$ but their substitution into the genome of a daptomycin-susceptible strain did not detectably increase resistance. ${ }^{101}$ A study that comprehensively characterized the membrane lipid compositions of daptomycin-resistant Staphylococcus aureus strains found 
the expected decrease in PG, as well as an increase in lysyl-PG, but no significant change in CL. ${ }^{94}$ Since CL is formed from PG, it seems possible that CL synthase gain-of-function mutants merely compensate for the reduction in substrate levels.

\subsection{Cell wall permeability}

Enhanced expression of the $d l t$ operon has been found to occur in daptomycin-resistant strains of Staphylococcus aureus. ${ }^{98,102-106}$ The dlt operon is involved in the incorporation of D-alanine into cell wall teichoic acids. The alanylation of these surface-exposed structures results in an increase in the net positive charge of the cell surface, which may affect daptomycin's ability to function in the same manner as PG lysylation. Moreover, teichoic acid $\mathrm{D}$-alanylation reduces penetration of the cell wall by cationic antimicrobial peptides, ${ }^{107}$ a mechanism that also appears plausible with daptomycin.

\subsection{Mutations in the yycFG operon}

The $y y c F G$ operon is a hot spot for mutations conferring daptomycin resistance. It encodes the $y y c F G$ response regulator system, which controls cell wall metabolism and biofilm formation. ${ }^{108,109}$ in vitro -derived resistant mutants of Staphylococcus aureus exhibited changes affecting the histidine kinase of the system (YycG). ${ }^{110,111}$ In Bacillus subtilis, this protein is located at the cell division septum, where it regulates cell division and wall restructuring. ${ }^{112}$

Several mutations in different locations of the $y y c F G$ operon in daptomycinresistant S. aureus were reported by Howden et al., although their exact contribution to resistance is unclear. ${ }^{113}$ Nevertheless, a single amino acid change in YycG was sufficient to increase the MIC from 0.5 to $2 \mu \mathrm{g} / \mathrm{L}$, a value that is sufficient for clinical resistance. In Enterococcus faecium, mutations in the $y y c F G$ operon have also been found in daptomycin-resistant strains. ${ }^{101,114}$

Another line of evidence that connects $y y c G$ to daptomycin's MOA has been pointed out by Baltz. ${ }^{11}$ YycG is localized at the cell division septum, and inhibition of YycG causes aberrant cell division septa. Daptomycin binds preferentially at the cell division septum and also causes the formation of aberrant cell division septa (see section 10.10). Depletion of YycG causes rapid cell death without lysis, as does daptomycin (section 10.5). YycFG also positively regulates biofilm formation, while daptomycin treats $S$. aureus biofilms effectively. Baltz has therefore proposed that, in addition to the dissipation of membrane potential, daptomycin may also exert by directly inhibiting YycG. This hypothesis has yet to be addressed experimentally. 


\subsection{Activation of LiaRS}

The membrane-associated transcriptional regulator LiaRS is activated by antimicrobial peptides, as well as by antibiotics that interfere with cell wall synthesis. It is also activated by daptomycin, which in turn reduces bacterial daptomycin susceptibility. ${ }^{64,115}$

While LiaRS is found in all Gram-positive bacteria, interest has focused on Enterococcus species in the context of clinical daptomycin resistance. Arias and co-workers characterized LiaRS mutations in clinical isolates of Enterococcus faecalis and E. faecium that induce daptomycin resistance. ${ }^{116}$ In such strains, the activation of LiaRS greatly reduces the efficiency of daptomycin to bacterial cells. ${ }^{117}$

When activated, LiaRS induces the expression of LiaI and LiaH, which colocalize within segregated domains in the cytoplasmic membrane. ${ }^{118}$ The phenotypic effects of these effector molecules, and accordingly their role in daptomycin resistance, are not yet understood.

\section{Conclusion}

From the foregoing discussion, it will be clear that daptomycin's action mechanism is not fully understood. While the formation of oligomeric lesions that permeabilize and depolarize the cell membrane has been thoroughly documented and can account for the bactericidal activity, several lines of evidence suggest that daptomycin may also directly interfere with cell division and cell

wall synthesis. A precedent for such a dual mechanism of action is provided by the lantibiotic nisin. ${ }^{87,119}$

In addition to the mechanism of action, much work remains to be done regarding daptomycin's structure-activity relationships. A larger and more diverse set of sequence variants is needed, which should be examined for antimicrobial activity, but also using biophysical and biochemical methods that illuminate specific steps in the action mode of daptomycin. Such mechanistic studies should contribute to a more detailed understanding and hopefully enable the rational design of improved derivatives, which could address concerns such as emerging resistance and inhibition by lung surfactant.

Even if the above questions can be answered, daptomycin's complex structure will make it challenging to obtain the improved variants in sufficient amounts for therapeutic application. The most promising way forward may consist in a dual strategy that uses total synthesis ${ }^{52}$ on a scale sufficient for in vitro and animal studies, while the scaling up of successful variants for clinical 
testing and application would be pursued using the synthetase engineering techniques demonstrated by Nguyen et al. ${ }^{33,53}$

\section{Bibliography}

1. A. S. Bayer, T. Schneider, H.-G. Sahl, Mechanisms of daptomycin resistance in Staphylococcus aureus: role of the cell membrane and cell wall, Ann N Y Acad Sci 1277 (2013) 139-158. PubMed : 23215859.

2. T. T. Tran, J. M. Munita, C. A. Arias, Mechanisms of drug resistance: daptomycin resistance, Ann N Y Acad Sci 1354 (2015) 32-53. PubMed: 26495887.

3. B. I. Eisenstein, F. B. J. Oleson, R. H. Baltz, Daptomycin: from the mountain to the clinic, with essential help from Francis Tally, MD, Clin Infect Dis 50 Suppl 1 (2010) S10-S15. PubMed : 20067387.

4. N. Bionda, M. Stawikowski, R. Stawikowska, M. Cudic, F. López-Vallejo, D. Treitl, J. Medina-Franco, P. Cudic, Effects of cyclic lipodepsipeptide structural modulation on stability, antibacterial activity, and human cell toxicity, ChemMedChem 7 (2012) 871-882. PubMed : 22392790.

5. N. Bionda, J.-P. Pitteloud, P. Cudic, Cyclic lipodepsipeptides: a new class of antibacterial agents in the battle against resistant bacteria, Future Med Chem 5 (2013) 1311-1330. PubMed : 23859209.

6. E. G. Tótoli, S. Garg, H. R. N. Salgado, Daptomycin: Physicochemical, analytical, and pharmacological properties, Ther Drug Monit 37 (2015) 699-710. PubMed : 26020161.

7. C. Vilhena, A. Bettencourt, Daptomycin: a review of properties, clinical use, drug delivery and resistance, Mini Rev Med Chem 12 (2012) 202-209. PubMed : 22356191.

8. K. Nadrah, F. Strle, Antibiotic combinations with daptomycin for treatment of Staphylococcus aureus infections, Chemother Res Pract 2011 (2011) 619321. PubMed : 22312555.

9. L. Robbel, M. A. Marahiel, Daptomycin, a bacterial lipopeptide synthesized by a nonribosomal machinery, J Biol Chem 285 (2010) 27501-27508. PubMed : 20522545. 
10. M. Strieker, M. A. Marahiel, The structural diversity of acidic lipopeptide antibiotics, Chembiochem 10 (2009) 607-616. PubMed: 19156787.

11. R. H. Baltz, Daptomycin: mechanisms of action and resistance, and biosynthetic engineering, Curr Opin Chem Biol 13 (2009) 144-151. PubMed: 19303806.

12. R. Sauermann, M. Rothenburger, W. Graninger, C. Joukhadar, Daptomycin: a review 4 years after first approval, Pharmacology 81 (2008) 79-91. PubMed: 17940348.

13. B. I. Eisenstein, Treatment of staphylococcal infections with cyclic lipopeptides, Clin Microbiol Infect 14 Suppl 2 (2008) 10-16. PubMed: 18226085.

14. S. K. Straus, R. E. W. Hancock, Mode of action of the new antibiotic for Gram-positive pathogens daptomycin: comparison with cationic antimicrobial peptides and lipopeptides, Biochim Biophys Acta 1758 (2006) 1215-1223. PubMed: 16615993.

15. J. N. Steenbergen, J. Alder, G. M. Thorne, F. P. Tally, Daptomycin: a lipopeptide antibiotic for the treatment of serious Gram-positive infections, J Antimicrob Chemother 55 (2005) 283-288. PubMed: 15705644.

16. R. H. Baltz, V. Miao, S. K. Wrigley, Natural products to drugs: daptomycin and related lipopeptide antibiotics, Nat Prod Rep 22 (2005) 717741. PubMed: 16311632.

17. F. P. Tally, M. F. DeBruin, Development of daptomycin for Gram-positive infections, J Antimicrob Chemother 46 (2000) 523-526. PubMed: 11020247.

18. M. Debono, M. Barnhart, C. B. Carrell, J. A. Hoffman, R. L. Hamill, A219778C, a complex of new acidic peptide antibiotics: Factor definition and preliminary chemical characterization, in: Program and abstracts of 20th Intersci. Conference on Antimicrobial Agents and Chemotherapy, 1980.

19. F. Counter, P. W. Ensminger, L. C. Howard, A21978C, a complex of new acidic lipopeptide antibiotics: Biological activity and toxicity, in: Program and abstracts of the 20th Intersci. Conference on Antimicrobial Agents and Chemotherapy, 1980. 
20. F. B. J. Oleson, C. L. Berman, J. B. Kirkpatrick, K. S. Regan, J. J. Lai, F. P. Tally, Once-daily dosing in dogs optimizes daptomycin safety, Antimicrob Agents Chemother 44 (2000) 2948-2953. PubMed:11036005.

21. J. A. Silverman, L. I. Mortin, A. D. G. Vanpraagh, T. Li, J. Alder, Inhibition of daptomycin by pulmonary surfactant: in vitro modeling and clinical impact, J Infect Dis 191 (2005) 2149-2152. PubMed: 15898002.

22. R. H. Baltz, Combinatorial biosynthesis of cyclic lipopeptide antibiotics: a model for synthetic biology to accelerate the evolution of secondary metabolite biosynthetic pathways, ACS Synth Biol 3 (2014) 748-758. PubMed: 23654258.

23. M. Debono, M. Barnhart, C. B. Carrell, J. A. Hoffmann, J. L. Occolowitz, B. J. Abbott, D. S. Fukuda, R. L. Hamill, K. Biemann, W. C. Herlihy, A21978C, a complex of new acidic peptide antibiotics: isolation, chemistry, and mass spectral structure elucidation, J Antibiot (Tokyo) 40 (1987) 761-777. PubMed:3610833.

24. V. Miao, M.-F. Coëffet-Legal, P. Brian, R. Brost, J. Penn, A. Whiting, S. Martin, R. Ford, I. Parr, M. Bouchard, C. J. Silva, S. K. Wrigley, R. H. Baltz, Daptomycin biosynthesis in Streptomyces roseosporus: cloning and analysis of the gene cluster and revision of peptide stereochemistry, Microbiology 151 (2005) 1507-1523. PubMed: 15870461.

25. J. K. Muraih, Mode of action of daptomycin, a lipopeptide antibiotic, Ph.D. thesis, University of Waterloo (2012).

26. M. Debono, B. J. Abbott, R. M. Molloy, D. S. Fukuda, A. H. Hunt, V. M. Daupert, F. T. Counter, J. L. Ott, C. B. Carrell, L. C. Howard, Enzymatic and chemical modifications of lipopeptide antibiotic A21978C: the synthesis and evaluation of daptomycin (LY146032), J Antibiot (Tokyo) 41 (1988) 1093-1105. PubMed : 2844711.

27. F. M. Huber, R. L. Pieper, A. J. Tietz, The formation of daptomycin by supplying decanoic acid to Streptomyces roseosporus cultures producing the antibiotic complex A21978C, Journal of Biotechnology 7 (1988) 283292.

URL http://dx.doi.org/10.1016/0168-1656(88)90040-5 
28. H. Tanaka, Y. Iwai, R. Oiwa, S. Shinohara, S. Shimizu, T. Oka, S. Omura, Studies on bacterial cell wall inhibitors. II. Inhibition of peptidoglycan synthesis in vivo and in vitro by amphomycin, Biochim Biophys Acta 497 (1977) 633-640. PubMed:407940.

29. H. Tanaka, R. Oiwa, S. Matsukura, S. Omura, Amphomycin inhibits phospho-N-acetylmuramyl-pentapeptide translocase in peptidoglycan synthesis of Bacillus, Biochem Biophys Res Commun 86 (1979) 902-908. PubMed: 106855.

30. T. Schneider, K. Gries, M. Josten, I. Wiedemann, S. Pelzer, H. Labischinski, H. . G. Sahl, The lipopeptide antibiotic Friulimicin B inhibits cell wall biosynthesis through complex formation with bactoprenol phosphate, Antimicrob Agents Chemother 53 (2009) 1610-1618. PubMed: 19164139.

31. L. H. J. Kleijn, S. F. Oppedijk, P. 't Hart, R. M. van Harten, L. A. MartinVisscher, J. Kemmink, E. Breukink, N. I. Martin, Total synthesis of laspartomycin c and characterization of its antibacterial mechanism of action, J Med Chem 59 (2016) 3569-3574. PubMed : 26967152.

32. E. Rubinchik, T. Schneider, M. Elliott, W. R. P. Scott, J. Pan, C. Anklin, H. Yang, D. Dugourd, A. Müller, K. Gries, S. K. Straus, H. G. Sahl, R. E. W. Hancock, Mechanism of action and limited cross-resistance of new lipopeptide MX-2401, Antimicrob Agents Chemother 55 (2011) 27432754. PubMed: 21464247.

33. K. T. Nguyen, X. He, D. C. Alexander, C. Li, J.-Q. Gu, C. Mascio, A. V. Praagh, L. Mortin, M. Chu, J. A. Silverman, P. Brian, R. H. Baltz, Genetically engineered lipopeptide antibiotics related to a54145 and daptomycin with improved properties, Antimicrob Agents Chemother 54 (2010) 1404-1413. PubMed : 20086142.

34. L. E. Kirsch, R. M. Molloy, M. Debono, P. Baker, K. Z. Farid, Kinetics of the aspartyl transpeptidation of daptomycin, a novel lipopeptide antibiotic, Pharm Res 6 (1989) 387-393. PubMed : 2546142.

35. J. Qiu, L. Yu, L. E. Kirsch, Estimated pKa values for specific amino acid residues in daptomycin, J Pharm Sci 100 (2011) 4225-4233. PubMed: 21547914. 
36. L.-J. Ball, C. M. Goult, J. A. Donarski, J. Micklefield, V. Ramesh, NMR structure determination and calcium binding effects of lipopeptide antibiotic daptomycin, Org Biomol Chem 2 (2004) 1872-1878. PubMed: 15227539.

37. S. W. Ho, D. Jung, J. R. Calhoun, J. D. Lear, M. Okon, W. R. P. Scott, R. E. W. Hancock, S. K. Straus, Effect of divalent cations on the structure of the antibiotic daptomycin, Eur Biophys J 37 (2008) 421-433. PubMed: 17968536.

38. J. H. Lakey, M. Ptak, Fluorescence indicates a calcium-dependent interaction between the lipopeptide antibiotic LY146032 and phospholipid membranes, Biochemistry 27 (1988) 4639-4645. PubMed : 2844233.

39. K. S. Rotondi, L. M. Gierasch, A well-defined amphipathic conformation for the calcium-free cyclic lipopeptide antibiotic, daptomycin, in aqueous solution, Biopolymers 80 (2005) 374-385. PubMed : 15815985.

40. J. Qiu, L. E. Kirsch, Evaluation of lipopeptide (daptomycin) aggregation using fluorescence, light scattering, and nuclear magnetic resonance spectroscopy, J Pharm Sci 103 (2014) 853-861. PubMed : 24464772.

41. D. Jung, J. P. Powers, S. K. Straus, R. E. W. Hancock, Lipid-specific binding of the calcium-dependent antibiotic daptomycin leads to changes in lipid polymorphism of model membranes, Chem Phys Lipids 154 (2008) 120128. PubMed: 18489906.

42. D. Jung, A. Rozek, M. Okon, R. E. W. Hancock, Structural transitions as determinants of the action of the calcium-dependent antibiotic daptomycin., Chem Biol 11 (2004) 949-957. PubMed: 15271353.

43. B. H. Dvorchik, D. Brazier, M. F. DeBruin, R. D. Arbeit, Daptomycin pharmacokinetics and safety following administration of escalating doses once daily to healthy subjects, Antimicrob Agents Chemother 47 (2003) 1318-1323. PubMed : 12654665.

44. M. Benvenuto, D. P. Benziger, S. Yankelev, G. Vigliani, Pharmacokinetics and tolerability of daptomycin at doses up to 12 milligrams per kilogram of body weight once daily in healthy volunteers, Antimicrob Agents Chemother 50 (2006) 3245-3249. PubMed: 17005801. 
45. J. K. Muraih, A. Pearson, J. Silverman, M. Palmer, Oligomerization of daptomycin on membranes, Biochim Biophys Acta 1808 (2011) 1154-1160. PubMed:21223947.

46. G. Bunkóczi, L. Vértesy, G. M. Sheldrick, Structure of the lipopeptide antibiotic tsushimycin, Acta Crystallogr D Biol Crystallogr 61 (2005) 11601164. PubMed: 16041082.

47. W. R. P. Scott, S.-B. Baek, D. Jung, R. E. W. Hancock, S. K. Straus, NMR structural studies of the antibiotic lipopeptide daptomycin in DHPC micelles, Biochim Biophys Acta 1768 (2007) 3116-3126. PubMed: 17945184.

48. M. Yazawa, K. Yagi, The amino acid sequence of the calmodulin obtained from sea anemone (Metridium senile) muscle, Biochem Biophys Res Commun 96 (1980) 377-381. PubMed:6108109.

49. C. R. Lohani, R. Taylor, M. Palmer, S. D. Taylor, Solid-phase synthesis and in vitro biological activity of a Thr4 $\rightarrow$ Ser4 analog of daptomycin, Bioorg Med Chem Lett 25 (2015) 5490-5494. PubMed : 26520664.

50. J. Grünewald, S. A. Sieber, C. Mahlert, U. Linne, M. A. Marahiel, Synthesis and derivatization of daptomycin: a chemoenzymatic route to acidic lipopeptide antibiotics, J Am Chem Soc 126 (2004) 17025-17031. PubMed: 15612741.

51. J. K. Muraih, J. Harris, S. D. Taylor, M. Palmer, Characterization of daptomycin oligomerization with perylene excimer fluorescence: stoichiometric binding of phosphatidylglycerol triggers oligomer formation, Biochim Biophys Acta 1818 (2012) 673-678. PubMed : 22079564.

52. C. Lohani, R. Taylor, M. Palmer, S. Taylor, Solid-phase total synthesis of daptomycin and analogs, Organic Letters 17 (2015) 748-751. PubMed: 25634084.

53. K. T. Nguyen, D. Ritz, J.-Q. Gu, D. Alexander, M. Chu, V. Miao, P. Brian, R. H. Baltz, Combinatorial biosynthesis of novel antibiotics related to daptomycin, Proc Natl Acad Sci U S A 103 (2006) 17462-17467. PubMed: 17090667.

54. P. 't Hart, L. H. J. Kleijn, G. de Bruin, S. F. Oppedijk, J. Kemmink, N. I. Martin, A combined solid- and solution-phase approach provides convenient 
access to analogues of the calcium-dependent lipopeptide antibiotics, Org Biomol Chem 12 (2014) 913-918. PubMed : 24346297.

55. Y. He, J. Li, N. Yin, P. S. Herradura, L. Martel, Y. Zhang, A. L. Pearson, V. Kulkarni, C. Mascio, K. Howland, J. A. Silverman, D. D. Keith, C. A. Metcalf, Reduced pulmonary surfactant interaction of daptomycin analogs via tryptophan replacement with alternative amino acids, Bioorg Med Chem Lett 22 (2012) 6248-6251. PubMed : 22951041.

56. J. Hill, J. Siedlecki, I. Parr, M. Morytko, X. Yu, Y. Zhang, J. Silverman, N. Controneo, V. Laganas, T. Li, J.-J. Lai, D. Keith, G. Shimer, J. Finn, Synthesis and biological activity of N-Acylated ornithine analogues of daptomycin, Bioorg Med Chem Lett 13 (2003) 4187-4191. PubMed: 14622998.

57. J. Siedlecki, J. Hill, I. Parr, X. Yu, M. Morytko, Y. Zhang, J. Silverman, N. Controneo, V. Laganas, T. Li, J. Li, D. Keith, G. Shimer, J. Finn, Array synthesis of novel lipodepsipeptide, Bioorg Med Chem Lett 13 (2003) 42454249. PubMed: 14623010.

58. N. E. Allen, J. N. Hobbs, W. E. J. Alborn, Inhibition of peptidoglycan biosynthesis in Gram-positive bacteria by LY146032, Antimicrob Agents Chemother 31 (1987) 1093-1099. PubMed: 2821889.

59. P. Canepari, M. Boaretti, M. M. Lleó, G. Satta, Lipoteichoic acid as a new target for activity of antibiotics: mode of action of daptomycin (LY146032), Antimicrob Agents Chemother 34 (1990) 1220-1226. PubMed: 2168145 .

60. J. H. Lakey, E. J. Lea, The role of acyl chain character and other determinants on the bilayer activity of A21978C, an acidic lipopeptide antibiotic, Biochim Biophys Acta 859 (1986) 219-226. PubMed : 3730378.

61. J. H. Lakey, R. Maget-Dana, M. Ptak, The lipopeptide antibiotic A21978C has a specific interaction with DMPC only in the presence of calcium ions, Biochim Biophys Acta 985 (1989) 60-66. PubMed : 2790047.

62. R. M. Epand, S. Rotem, A. Mor, B. Berno, R. F. Epand, Bacterial membranes as predictors of antimicrobial potency, J Am Chem Soc 130 (2008) 1434614352. PubMed: 18826221. 
63. T. Zhang, J. K. Muraih, E. Mintzer, N. Tishbi, C. Desert, J. Silverman, S. Taylor, M. Palmer, Mutual inhibition through hybrid oligomer formation of daptomycin and the semisynthetic lipopeptide antibiotic CB-182,462, Biochim Biophys Acta 1828 (2013) 302-308. PubMed: 23084999.

64. A.-B. Hachmann, E. R. Angert, J. D. Helmann, Genetic analysis of factors affecting susceptibility of Bacillus subtilis to daptomycin, Antimicrob Agents Chemother 53 (2009) 1598-1609. PubMed: 19164152.

65. S. G. Batrakov, L. D. Bergelson, Lipids of the Streptomycetes. Structural investigation and biological interrelation a review, Chem Phys Lipids 21 (1978) 1-29. PubMed: 96946.

66. T. Zhang, J. K. Muraih, N. Tishbi, J. Herskowitz, R. L. Victor, J. Silverman, S. Uwumarenogie, S. D. Taylor, M. Palmer, E. Mintzer, Cardiolipin prevents membrane translocation and permeabilization by daptomycin, J Biol Chem 289 (2014) 11584-11591. PubMed : 24616102.

67. T. T. Tran, D. Panesso, N. N. Mishra, E. Mileykovskaya, Z. Guan, J. M. Munita, J. Reyes, L. Diaz, G. M. Weinstock, B. E. Murray, Y. Shamoo, W. Dowhan, A. S. Bayer, C. A. Arias, Daptomycin-resistant Enterococcus faecalis diverts the antibiotic molecule from the division septum and remodels cell membrane phospholipids, MBio 4. PubMed : 23882013.

68. P. M. Oliver, J. A. Crooks, M. Leidl, E. J. Yoon, A. Saghatelian, D. B. Weibel, Localization of anionic phospholipids in Escherichia coli cells, J Bacteriol 196 (2014) 3386-3398. PubMed : 25002539.

69. J. Goerke, Pulmonary surfactant: functions and molecular composition, Biochim Biophys Acta 1408 (1998) 79-89. PubMed : 9813251.

70. M. Boaretti, P. Canepari, Identification of daptomycin-binding proteins in the membrane of Enterococcus hirae, Antimicrob Agents Chemother 39 (1995) 2068-2072. PubMed : 8540717.

71. M. Boaretti, P. Canepari, Purification of daptomycin binding proteins (DBPs) from the membrane of Enterococcus hirae, New Microbiol 23 (2000) 305-317. PubMed: 10939046. 
72. J. Pogliano, N. Pogliano, J. A. Silverman, Daptomycin-mediated reorganization of membrane architecture causes mislocalization of essential cell division proteins, J Bacteriol 194 (2012) 4494-4504. PubMed: 22661688.

73. J. A. Silverman, N. G. Perlmutter, H. M. Shapiro, Correlation of daptomycin bactericidal activity and membrane depolarization in Staphylococcus aureus, Antimicrob Agents Chemother 47 (2003) 2538-2544.

74. W. E. J. Alborn, N. E. Allen, D. A. Preston, Daptomycin disrupts membrane potential in growing Staphylococcus aureus, Antimicrob Agents Chemother 35 (1991) 2282-2287. PubMed: 1666494.

75. N. E. Allen, W. E. J. Alborn, J. N. J. Hobbs, Inhibition of membrane potential-dependent amino acid transport by daptomycin, Antimicrob Agents Chemother 35 (1991) 2639-2642. PubMed: 1687346.

76. N. Cotroneo, R. Harris, N. Perlmutter, T. Beveridge, J. A. Silverman, Daptomycin exerts bactericidal activity without lysis of Staphylococcus aureus, Antimicrob Agents Chemother 52 (2008) 2223-2225. PubMed: 18378708.

77. L. J. Wale, A. P. Shelton, D. Greenwood, Scanning electronmicroscopy of Staphylococcus aureus and Enterococcus faecalis exposed to daptomycin, J Med Microbiol 30 (1989) 45-49. PubMed : 2550648.

78. D. Patel, C. Kosmidis, S. M. Seo, G. W. Kaatz, Ethidium bromide MIC screening for enhanced efflux pump gene expression or efflux activity in Staphylococcus aureus, Antimicrob Agents Chemother 54 (2010) 50705073. PubMed: 20855743.

79. J. K. Hobbs, K. Miller, A. J. O'Neill, I. Chopra, Consequences of daptomycin-mediated membrane damage in Staphylococcus aureus, J Antimicrob Chemother 62 (2008) 1003-1008. PubMed:18669516.

80. N. R. Clement, J. M. Gould, Pyranine (8-hydroxy-1,3,6pyrenetrisulfonate) as a probe of internal aqueous hydrogen ion concentration in phospholipid vesicles, Biochemistry 20 (1981) 15341538. PubMed:6261798.

81. T. Zhang, J. Muraih, B. MacCormick, J. Silverman, M. Palmer, Daptomycin forms cation- and size-selective pores in model membranes, Biochim Biophys Acta 1838 (2014) 2425-2430. PubMed : 24857935. 
82. V. Laganas, J. Alder, J. A. Silverman, In vitro bactericidal activities of daptomycin against Staphylococcus aureus and Enterococcus faecalis are not mediated by inhibition of lipoteichoic acid biosynthesis, Antimicrob Agents Chemother 47 (2003) 2682-2684.

83. J. K. Muraih, M. Palmer, Estimation of the subunit stoichiometry of the membrane-associated daptomycin oligomer by FRET, Biochim Biophys Acta 1818 (2012) 1642-1647. PubMed : 22387459.

84. T. Zhang, S. Taylor, M. Palmer, J. Duhamel, Membrane binding and oligomer formation of the calcium-dependent lipopeptide antibiotic A54145: a quantitative study with pyrene excimer fluorescence, Biophys J (submitted).

85. R. M. Taylor, K. Butt, B. Scott, J. K. Muraih, T. Zhang, S. D. Taylor, M. Palmer, E. M. Mintzer, Two successive calcium-dependent transitions mediate membrane binding and oligomerization of daptomycin and the related antibiotic A54145, BBA Biomembranes (submitted).

86. Y.-F. Chen, T.-L. Sun, Y. Sun, H. W. Huang, Interaction of daptomycin with lipid bilayers: a lipid extracting effect, Biochemistry 53 (2014) 5384-5392. PubMed:25093761.

87. I. Wiedemann, E. Breukink, C. van Kraaij, O. P. Kuipers, G. Bierbaum, B. de Kruifff, H. G. Sahl, Specific binding of nisin to the peptidoglycan precursor lipid II combines pore formation and inhibition of cell wall biosynthesis for potent antibiotic activity, J Biol Chem 276 (2001) 17721779. PubMed: 11038353.

88. G. M. Eliopoulos, C. Thauvin, B. Gerson, R. C. J. Moellering, In vitro activity and mechanism of action of $\mathrm{A} 21978 \mathrm{C} 1$, a novel cyclic lipopeptide antibiotic, Antimicrob Agents Chemother 27 (1985) 357-362. PubMed: 3994349.

89. D. Mengin-Lecreulx, N. E. Allen, J. N. Hobbs, J. van Heijenoort, Inhibition of peptidoglycan biosynthesis in Bacillus megaterium by daptomycin, FEMS Microbiol Lett 57 (1990) 245-248. PubMed: 2170230.

90. A.-B. Hachmann, E. Sevim, A. Gaballa, D. L. Popham, H. Antelmann, J. D. Helmann, Reduction in membrane phosphatidylglycerol content leads to 
daptomycin resistance in Bacillus subtilis, Antimicrob Agents Chemother 55 (2011) 4326-4337. PubMed : 21709092.

91. A. Y. Peleg, S. Miyakis, D. V. Ward, A. M. Earl, A. Rubio, D. R. Cameron, S. Pillai, R. C. J. Moellering, G. M. Eliopoulos, Whole genome characterization of the mechanisms of daptomycin resistance in clinical and laboratory derived isolates of Staphylococcus aureus, PLoS One 7 (2012) e28316. PubMed: 22238576.

92. P. Staubitz, H. Neumann, T. Schneider, I. Wiedemann, A. Peschel, MprFmediated biosynthesis of lysylphosphatidylglycerol, an important determinant in staphylococcal defensin resistance, FEMS Microbiol Lett 231 (2004) 67-71. PubMed: 14769468.

93. A. Peschel, R. W. Jack, M. Otto, L. V. Collins, P. Staubitz, G. Nicholson, H. Kalbacher, W. F. Nieuwenhuizen, G. Jung, A. Tarkowski, K. P. van Kessel, J. A. van Strijp, Staphylococcus aureus resistance to human defensins and evasion of neutrophil killing via the novel virulence factor MprF is based on modification of membrane lipids with l-lysine, J Exp Med 193 (2001) 1067-1076. PubMed:11342591.

94. N. N. Mishra, A. S. Bayer, Correlation of cell membrane lipid profiles with daptomycin resistance in methicillin-resistant Staphylococcus aureus, Antimicrob Agents Chemother 57 (2013) 1082-1085. PubMed : 23254419.

95. D. R. Cameron, L. I. Mortin, A. Rubio, E. Mylonakis, R. C. J. Moellering, G. M. Eliopoulos, A. Y. Peleg, Impact of daptomycin resistance on Staphylococcus aureus virulence, Virulence 6 (2015) 127-131. PubMed: 25830650.

96. E. Kilelee, A. Pokorny, M. R. Yeaman, A. S. Bayer, Lysylphosphatidylglycerol attenuates membrane perturbation rather than surface association of the cationic antimicrobial peptide 6w-rp-1 in a model membrane system: Implications for daptomycin resistance, Antimicrob Agents ChemotherPubMed: 20660664.

97. S. K. Pillai, H. S. Gold, G. Sakoulas, C. Wennersten, R. C. J. Moellering, G. M. Eliopoulos, Daptomycin nonsusceptibility in Staphylococcus aureus with reduced vancomycin susceptibility is independent of alterations in MprF, Antimicrob Agents Chemother 51 (2007) 2223-2225. PubMed: 17404001. 
98. N. N. Mishra, A. S. Bayer, C. Weidenmaier, T. Grau, S. Wanner, S. Stefani, V. Cafiso, T. Bertuccio, M. R. Yeaman, C. C. Nast, S.-J. Yang, Phenotypic and genotypic characterization of daptomycin-resistant methicillinresistant Staphylococcus aureus strains: relative roles of mprF and dlt operons, PLoS One 9 (2014) e107426. PubMed: 25226591.

99. K. L. Palmer, A. Daniel, C. Hardy, J. Silverman, M. S. Gilmore, Genetic basis for daptomycin resistance in enterococci, Antimicrob Agents Chemother 55 (2011) 3345-3356. PubMed : 21502617.

100. M. Davlieva, W. Zhang, C. A. Arias, Y. Shamoo, Biochemical characterization of cardiolipin synthase mutations associated with daptomycin resistance in enterococci, Antimicrob Agents Chemother 57 (2013) 289296. PubMed : 23114777.

101. T. T. Tran, D. Panesso, H. Gao, J. H. Roh, J. M. Munita, J. Reyes, L. Diaz, E. A. Lobos, Y. Shamoo, N. N. Mishra, A. S. Bayer, B. E. Murray, G. M. Weinstock, C. A. Arias, Whole-genome analysis of a daptomycin-susceptible Enterococcus faecium strain and its daptomycin-resistant variant arising during therapy, Antimicrob Agents Chemother 57 (2013) 261-268. PubMed : 23114757.

102. U. Bertsche, S.-J. Yang, D. Kuehner, S. Wanner, N. N. Mishra, T. Roth, M. Nega, A. Schneider, C. Mayer, T. Grau, A. S. Bayer, C. Weidenmaier, Increased cell wall teichoic acid production and D-alanylation are common phenotypes among daptomycin-resistant methicillin-resistant Staphylococcus aureus (MRSA) clinical isolates, PLoS One 8 (2013) e67398. PubMed : 23785522.

103. V. Cafiso, T. Bertuccio, S. Purrello, F. Campanile, C. Mammina, A. Sartor, A. Raglio, S. Stefani, dltA overexpression: A strain-independent keystone of daptomycin resistance in methicillin-resistant Staphylococcus aureus, Int J Antimicrob Agents 43 (2014) 26-31. PubMed : 24183798.

104. A. Fischer, S.-J. Yang, A. S. Bayer, A. R. Vaezzadeh, S. Herzig, L. Stenz, M. Girard, G. Sakoulas, A. Scherl, M. R. Yeaman, R. A. Proctor, J. Schrenzel, P. François, Daptomycin resistance mechanisms in clinically derived Staphylococcus aureus strains assessed by a combined transcriptomics and proteomics approach, J Antimicrob Chemother 66 (2011) 1696-1711. PubMed : 21622973. 
105. U. Bertsche, C. Weidenmaier, D. Kuehner, S.-J. Yang, S. Baur, S. Wanner, P. Francois, J. Schrenzel, M. R. Yeaman, A. S. Bayer, Correlation of daptomycin resistance in a clinical Staphylococcus aureus strain with increased cell wall teichoic acid production and D-alanylation, Antimicrob Agents Chemother 55 (2011) 3922-3928. PubMed: 21606222.

106. S.-J. Yang, B. N. Kreiswirth, G. Sakoulas, M. R. Yeaman, Y. Q. Xiong, A. Sawa, A. S. Bayer, Enhanced expression of dltABCD is associated with the development of daptomycin nonsusceptibility in a clinical endocarditis isolate of Staphylococcus aureus, J Infect Dis 200 (2009) 1916-1920. PubMed: 19919306.

107. R. Saar-Dover, A. Bitler, R. Nezer, L. Shmuel-Galia, A. Firon, E. Shimoni, P. Trieu-Cuot, Y. Shai, D-alanylation of lipoteichoic acids confers resistance to cationic peptides in group B streptococcus by increasing the cell wall density, PLoS Pathog 8 (2012) e1002891. PubMed: 22969424.

108. S. Dubrac, I. G. Boneca, O. Poupel, T. Msadek, New insights into the WalK/WalR (YycG/YycF) essential signal transduction pathway reveal a major role in controlling cell wall metabolism and biofilm formation in Staphylococcus aureus, J Bacteriol 189 (2007) 8257-8269. PubMed: 17827301.

109. M. E. Winkler, J. A. Hoch, Essentiality, bypass, and targeting of the YycFG (VicRK) two-component regulatory system in Gram-positive bacteria, J Bacteriol 190 (2008) 2645-2648. PubMed: 18245295.

110. L. Friedman, J. D. Alder, J. A. Silverman, Genetic changes that correlate with reduced susceptibility to daptomycin in Staphylococcus aureus, Antimicrob Agents Chemother 50 (2006) 2137-2145. PubMed: 16723576.

111. N. N. Mishra, J. McKinnell, M. R. Yeaman, A. Rubio, C. C. Nast, L. Chen, B. N. Kreiswirth, A. S. Bayer, In vitro cross-resistance to daptomycin and host defense cationic antimicrobial peptides in clinical methicillinresistant Staphylococcus aureus isolates, Antimicrob Agents Chemother 55 (2011) 4012-4018. PubMed: 21709105.

112. T. Fukushima, H. Szurmant, E.-J. Kim, M. Perego, J. A. Hoch, A sensor histidine kinase co-ordinates cell wall architecture with cell division in Bacillus subtilis, Mol Microbiol 69 (2008) 621-632. PubMed: 18573169. 
113. B. P. Howden, C. R. E. McEvoy, D. L. Allen, K. Chua, W. Gao, P. F. Harrison, J. Bell, G. Coombs, V. Bennett-Wood, J. L. Porter, R. Robins-Browne, J. K. Davies, T. Seemann, T. P. Stinear, Evolution of multidrug resistance during Staphylococcus aureus infection involves mutation of the essential two component regulator WalKR, PLoS Pathog 7 (2011) e1002359. PubMed: 22102812.

114. L. Diaz, T. T. Tran, J. M. Munita, W. R. Miller, S. Rincon, L. P. Carvajal, A. Wollam, J. Reyes, D. Panesso, N. L. Rojas, Y. Shamoo, B. E. Murray, G. M. Weinstock, C. A. Arias, Whole-genome analyses of Enterococcus faecium isolates with diverse daptomycin MICs, Antimicrob Agents Chemother 58 (2014) 4527-4534. PubMed: 24867964.

115. T. Wecke, D. Zühlke, U. Mäder, S. Jordan, B. Voigt, S. Pelzer, H. Labischinski, G. Homuth, M. Hecker, T. Mascher, Daptomycin versus Friulimicin B: in-depth profiling of Bacillus subtilis cell envelope stress responses, Antimicrob Agents Chemother 53 (2009) 1619-1623. PubMed: 19164157.

116. C. A. Arias, D. Panesso, D. M. McGrath, X. Qin, M. F. Mojica, C. Miller, L. Diaz, T. T. Tran, S. Rincon, E. M. Barbu, J. Reyes, J. H. Roh, E. Lobos, E. Sodergren, R. Pasqualini, W. Arap, J. P. Quinn, Y. Shamoo, B. E. Murray, G. M. Weinstock, Genetic basis for in vivo daptomycin resistance in enterococci, N Engl J Med 365 (2011) 892-900. PubMed:21899450.

117. D. Panesso, J. Reyes, E. P. Gaston, M. Deal, A. Londoño, M. Nigo, J. M. Munita, W. R. Miller, Y. Shamoo, T. T. Tran, C. A. Arias, Deletion of liar reverses daptomycin resistance in enterococcus faecium independent of the genetic background, Antimicrob Agents Chemother 59 (2015) 73277334. PubMed: 26369959.

118. J. Domínguez-Escobar, D. Wolf, G. Fritz, C. Höfler, R. Wedlich-Söldner, T. Mascher, Subcellular localization, interactions and dynamics of the phage-shock protein-like Lia response in Bacillus subtilis, Mol Microbiol 92 (2014) 716-732. PubMed: 24666271.

119. H. E. Hasper, B. de Kruijff, E. Breukink, Assembly and stability of nisinlipid II pores, Biochemistry 43 (2004) 11567-11575. PubMed: 15350143. 